\title{
Review \\ The Metabolism Reprogramming of microRNA Let-7-Mediated Glycolysis Contributes to Autophagy and Tumor Progression
}

\author{
Chien-Hsiu Li ${ }^{1}$ (D) and Chiao-Chun Liao ${ }^{2,3, *(\mathbb{D})}$ \\ 1 Genomics Research Center, Academia Sinica, Taipei 115, Taiwan; dicknivek@icloud.com \\ 2 Department of Tropical Medicine, National Yang Ming Chiao Tung University, Taipei 112, Taiwan \\ 3 Institute of Public Health and Department of Social Medicine, National Yang Ming Chiao Tung University, \\ Taipei 112, Taiwan \\ * Correspondence: Liaocc01@nycu.edu.tw; Tel.: +88-(62)-28267000; Fax: +88-(62)-28202190
}

Citation: Li, C.-H.; Liao, C.-C. The Metabolism Reprogramming of microRNA Let-7-Mediated

Glycolysis Contributes to Autophagy and Tumor Progression. Int. J. Mol. Sci. 2022, 23, 113. https://doi.org/ $10.3390 /$ ijms 23010113

Academic Editors: Cheorl-Ho Kim and Yu-Chan Chang

Received: 30 October 2021

Accepted: 20 December 2021

Published: 22 December 2021

Publisher's Note: MDPI stays neutral with regard to jurisdictional claims in published maps and institutional affiliations.

Copyright: (C) 2021 by the authors. Licensee MDPI, Basel, Switzerland. This article is an open access article distributed under the terms and conditions of the Creative Commons Attribution (CC BY) license (https:// creativecommons.org/licenses/by/ $4.0 /)$.

\begin{abstract}
Cancer is usually a result of abnormal glucose uptake and imbalanced nutrient metabolization. The dysregulation of glucose metabolism, which controls the processes of glycolysis, gives rise to various physiological defects. Autophagy is one of the metabolic-related cellular functions and involves not only energy regeneration but also tumorigenesis. The dysregulation of autophagy impacts on the imbalance of metabolic homeostasis and leads to a variety of disorders. In particular, the microRNA (miRNA) Let-7 has been identified as related to glycolysis procedures such as tissue repair, stem cell-derived cardiomyocytes, and tumoral metastasis. In many cancers, the expression of glycolysis-related enzymes is correlated with Let-7, in which multiple enzymes are related to the regulation of the autophagy process. However, much recent research has not comprehensively investigated how Let-7 participates in glycolytic reprogramming or its links to autophagic regulations, mainly in tumor progression. Through an integrated literature review and omics-related profiling correlation, this review provides the possible linkage of the Let-7 network between glycolysis and autophagy, and its role in tumor progression.
\end{abstract}

Keywords: glycolysis; autophagy; cancer; Let-7; microRNA

\section{Introduction}

Cellular energy-related metabolisms involve complex regulation dynamic processes. The current understanding is that the uptake of glucose from the extracellular environment is a primary way for cells to acquire resources for sustaining energy. Intermediate glucose metabolism can be converted by diverse metabolites of lipids and amino acids to maintain cellular functions [1]. In addition, autophagy is recognized as a digesting process to engulf cellular compartments or damaged organelles for maintaining metabolic homeostasis while responding to multiple metabolic stresses [2]. Within such processes, necessary molecules can be recycled by degrading specific factors to adapt cell growth to a rigorous environment. The glucose metabolic networks regulated by glycolysis and autophagy have explained the fundamental nutrients dynamic for maintaining cell growth and survival. Among them, miRNA, a 18-25-nt single-stranded noncoding RNA, serves as an essential modulator involved in cellular metabolisms, conducting post-transcriptional modification by targeting to 3'UTR of specific mRNA [3].

Let-7 is the first miRNA family identified as involved in multiple cellular and biological functions, including glucose metabolism and autophagy. The glucose metabolism is controlled by the miRNA family of Let-7 directly [4], or regulated by an autophagy-associated glycogen recycling system $[5,6]$. The imbalance of Let-7-mediated processes of glucose metabolism has been found to contribute to disease progression, especially carcinogenesis. In addition, metabolic dysregulation, which causes excessive energy release for unlimited growth, has been a consequential risk for promoting cancer development. However, the crosstalk networks between autophagy and glucose metabolism—especially the linkage of 
Let-7 miRNA that participates in carcinogenesis and various biological functions-are still obscure and need to be fully addressed.

In this review, the connection between the Let-7 family, glycolysis, and autophagy in glucose metabolism is comprehensively dissected and discussed. Accordingly, we also highlight the potent molecules and pathways involving glycolysis and autophagy and provide information on Let-7 family-associated linkage with disease progression, mainly in tumorigenesis. The interplay between Let-7, autophagy, and glucose metabolism is an aspect of disease progression that will provide extensive knowledge for developing alternative cancer treatment strategies by the regulation of cellular metabolism.

\section{Involvement of Let-7 in Glycolysis Reprogramming}

Let-7 was reported in 1990 and contributes to the embryonic development of C. elegans. The artificial manipulation of the expression of Let-7 causes mortality during embryogenesis [7]. Interestingly, several cancer-associated molecules have been identified from embryonic development, including Let-7. The Let-7 family has been classified by its consensus sequence [8] (Table 1). According to the literatures review, the Let-7 family-related expression was associated with the patient's prognosis (Table 2). Furthermore, numerous studies have indicated that the related expression of Let-7 is lower in tumor cells, whereas an increased level of Let-7 is able to suppress tumor malignancy, which indicates that Let-7 may contribute to the suppression role in most types of tumors $[9,10]$.

Table 1. The Let-7 family in humans.

\begin{tabular}{cc}
\hline Let-7 Family & Sequence \\
\hline Let-7a & UGAGGUAGUAGGUUGUAUAGUU \\
Let-7b & UGAGGUAGUAGGUUGUGUGGUU \\
Let-7c & UGAGGUAGUAGGUUGUAUGGUU \\
Let-7d & AGAGGUAGUAGGUUGCAUAGUU \\
Let-7e & UGAGGUAGGAGGUUGUAUAGUU \\
Let-7f & UGAGGUAGUAGAUUGUAUAGUU \\
Let-7g & UGAGGUAGUAGUUUGUACAGUU \\
Let-7i & UGAGGUAGUAGUUUGUGCUGUU \\
miR-98 & UGAGGUAGUAAGUUGUAUUGUU \\
miR-202 & AGAGGUAGUAGGGCAUGGGAA \\
\hline
\end{tabular}

There are divergent theories about how carcinogenesis starts. The monosaccharide glucose is the primary nutritarian for cells. After a meal, insulin increases and stimulates cell response to process glucose metabolism. Once cells uptake glucose, they undergo a process of glycolysis to convert glucose to other intermediates via specific enzymes and generate cellular components, including lipids, amino acids, and energy for cell survival [11]. According to the concept of cancer energy uptake raised by Douglas Hanahan and Robert Weinberg, the dysregulation of metabolism contributes to cancer progression [12]. Studies have demonstrated that the glucose level might change the mitochondria respiration in cells by modulating the expression of the Let-7 level [13]. Comprehensive miRNA profiling from 14 global population studies indicated that the top $1 \%$ of population-differentiated miRNA was associated with glucose/insulin metabolism and pathogenesis. MiR-202, as one of the Let-7 family members, may contribute to cancer progression by regulating glucose metabolism [14]. Additionally, Serguienko et al. observed that Let-7 is linked to the expression of Glucose-6-phosphate Dehydrogenase (G6PD), Inosine-5'-monophosphate dehydrogenase 2 (IMPDH2), Fatty Acid Synthase (FASN), stearoyl-CoA desaturase, and Aminoadipate-Semialdehyde Dehydrogenase-Phosphopantetheinyl Transferase (AASDHPPT) from a comparable transcriptome analysis [15]. We herein describe the molecular mechanism of Let-7-mediated glucose metabolism and Let-7-associated metabolic reprogramming impacts in tumor plasticity (Figure 1). 
Table 2. Let-7 family in pan-cancer on the basis of literature review to coordinate the related survival correlation between patients with cancer and the Let-7 family.

\begin{tabular}{|c|c|c|c|c|}
\hline Cancer Type & Let-7 Family & Clinical Association & Year & Reference \\
\hline \multirow{3}{*}{ Acute Myeloid Leukemia } & Let-7a & Associated with poor outcome & 2013 & [16] \\
\hline & \multirow{2}{*}{$\begin{array}{l}\text { Let-7a-2-3p } \\
\text { miR-98 }\end{array}$} & Associated with good outcome & 2015 & [17] \\
\hline & & Associated with good outcome & 2019 & [18] \\
\hline \multirow{28}{*}{ Breast Cancer } & Let-7a & Associated with good outcome & 2018 & [19] \\
\hline & Let-7a & Associated with good outcome & 2018 & [20] \\
\hline & Let-7a & Associated with good outcome & 2019 & [21] \\
\hline & Let-7a & Associated with good outcome & 2019 & [22] \\
\hline & Let-7a-5p & Associated with good outcome & 2020 & [23] \\
\hline & Let-7b & Associated with good outcome & 2018 & [19] \\
\hline & Let-7b & Associated with good outcome & 2019 & [21] \\
\hline & Let-7b & Associated with good outcome & 2020 & [24] \\
\hline & Let-7b & Associated with good outcome & 2020 & [25] \\
\hline & Let-7b & Associated with good outcome & 2020 & [26] \\
\hline & Let-7b & Associated with good outcome & 2016 & [27] \\
\hline & Let-7c & Associated with good outcome & 2016 & [27] \\
\hline & Let-7c & Associated with good outcome & 2018 & [19] \\
\hline & Let-7c & Associated with good outcome & 2019 & [21] \\
\hline & Let-7c & Associated with poor outcome & 2020 & [28] \\
\hline & Let-7d & Associated with good outcome & 2018 & [19] \\
\hline & Let-7d & Associated with good outcome & 2018 & [29] \\
\hline & Let-7d & Associated with good outcome & 2019 & [21] \\
\hline & Let-7e & Associated with good outcome & 2018 & [19] \\
\hline & Let-7e & Associated with poor outcome & 2019 & [21] \\
\hline & Let-7f & Associated with good outcome & 2018 & [19] \\
\hline & Let-7f & Associated with good outcome & 2019 & {$[21]$} \\
\hline & Let-7g & Associated with good outcome & 2011 & [30] \\
\hline & Let-7g & Associated with good outcome & 2018 & [19] \\
\hline & Let-7g & Associated with good outcome & 2019 & [21] \\
\hline & Let-7i & Associated with good outcome & 2008 & [31] \\
\hline & Let-7i & Associated with good outcome & 2018 & [19] \\
\hline & Let-7i & Associated with good outcome & 2019 & [21] \\
\hline \multirow{2}{*}{ Colon Cancer } & Let-7a & Associated with poor outcome & 2017 & [32] \\
\hline & Let-7g & Associated with good outcome & 2017 & [33] \\
\hline \multirow{3}{*}{ Esophageal Cancer } & Let-7b & Associated with good outcome & 2012 & [34] \\
\hline & Let-7c & Associated with good outcome & 2012 & [34] \\
\hline & Let-7c & Associated with good outcome & 2013 & [35] \\
\hline \multirow{4}{*}{ Glioblastoma } & Let-7a & Associated with good outcome & 2013 & [36] \\
\hline & Let-7c & Associated with good outcome & 2021 & [37] \\
\hline & Let-7f & Associated with poor outcome & 2018 & [38] \\
\hline & Let-7i & Associated with good outcome & 2020 & [39] \\
\hline \multirow{6}{*}{ Liver Cancer } & Let-7a & Associated with poor outcome & 2018 & [40] \\
\hline & Let-7a & Associated with good outcome & 2020 & [41] \\
\hline & Let-7b & Associated with good outcome & 2020 & [41] \\
\hline & Let-7b & Associated with good outcome & 2020 & [42] \\
\hline & Let-7c & Associated with good outcome & 2020 & [41] \\
\hline & miR-202 & Associated with good outcome & 2020 & [43] \\
\hline Lung Adenocarcinoma & Let-7b & Associated with good outcome & 2021 & {$[44]$} \\
\hline Melanoma & $\operatorname{miR}-98$ & Associated with good outcome & 2014 & {$[45]$} \\
\hline Mesothelioma & Let-7c & Associated with good outcome & 2017 & [46] \\
\hline
\end{tabular}


Table 2. Cont.

\begin{tabular}{|c|c|c|c|c|}
\hline Cancer Type & Let-7 Family & Clinical Association & Year & Reference \\
\hline \multirow{11}{*}{ Ovarian Cancer } & Let-7b & Associated with poor outcome & 2021 & [47] \\
\hline & Let-7d & Associated with poor outcome & 2012 & [48] \\
\hline & Let-7e & Associated with good outcome & 2017 & [49] \\
\hline & Let-7f & Associated with good outcome & 2013 & [50] \\
\hline & Let-7g & Associated with poor outcome & 2016 & [51] \\
\hline & Let-7i & Associated with good outcome & 2008 & [31] \\
\hline & miR-98 & Associated with good outcome & 2021 & [52] \\
\hline & miR-98 & Associated with good outcome & 2020 & [53] \\
\hline & miR-98 & Associated with poor outcome & 2019 & [54] \\
\hline & miR-98 & Associated with poor outcome & 2018 & [55] \\
\hline & miR-202 & Associated with good outcome & 2020 & [56] \\
\hline \multirow{3}{*}{ Pancreatic Cancer } & Let-7g & Associated with good outcome & 2017 & {$[57]$} \\
\hline & Let-7e & Associated with good outcome & 2010 & {$[58]$} \\
\hline & miR-202 & Associated with good outcome & 2021 & {$[59]$} \\
\hline \multirow{2}{*}{ Prostate Cancer } & Let-7b & Associated with poor outcome & 2013 & {$[60]$} \\
\hline & Let-7c & Associated with good outcome & 2013 & {$[60]$} \\
\hline
\end{tabular}

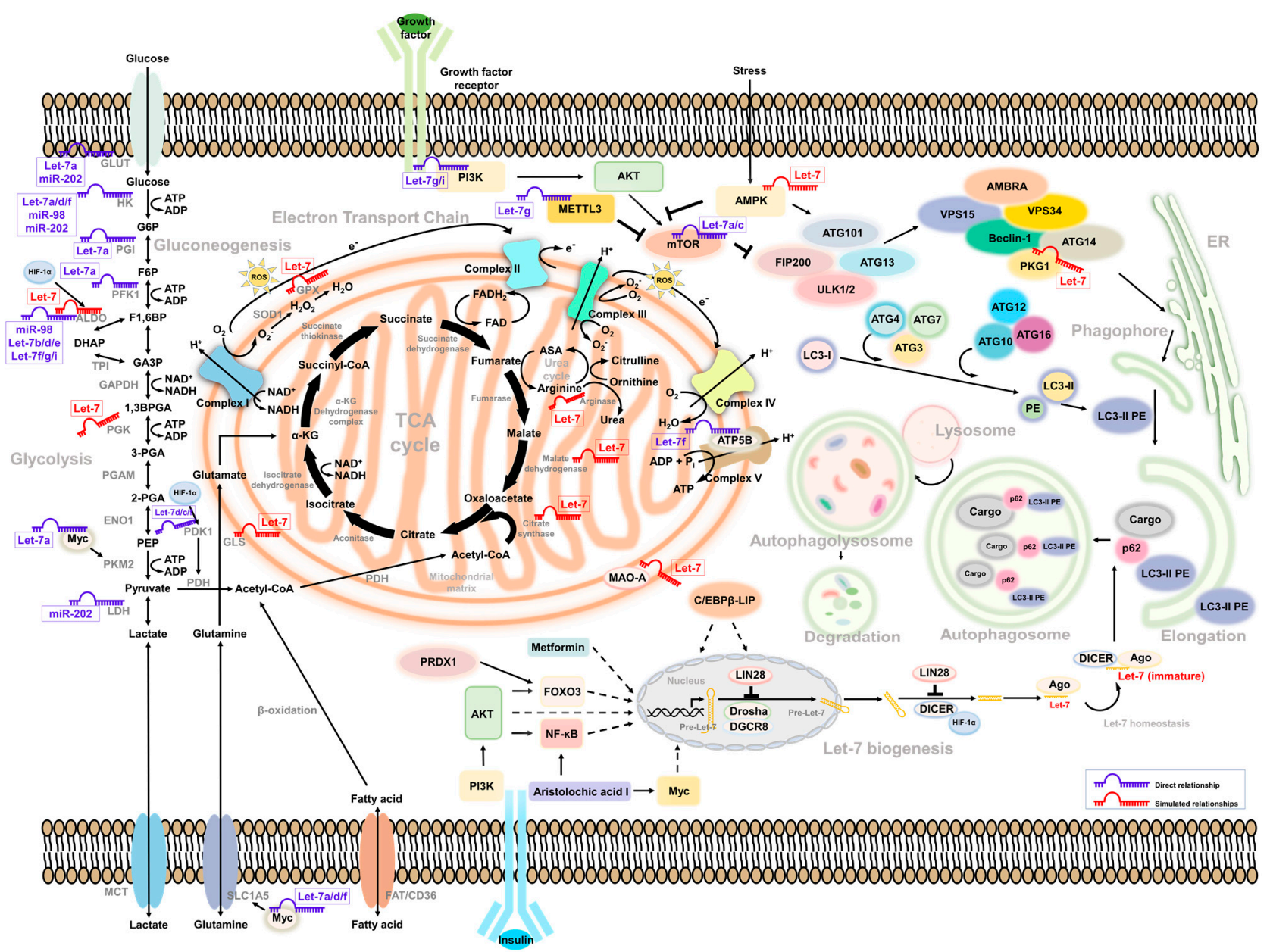

Figure 1. Intermediate mediators/molecules between Let-7-associated glucose metabolism and autophagy.

The diagram summarizes the current participation of the Let-7 family in the regulation of glucose metabolism and autophagy. The direct (marked blue) and indirect (marked red) interrelationship between glycolysis- and autophagy-related pathway were highlighted 
according to the simulated model. Molecules and factors involved in the biogenesis of Let-7 and the speculation of its interaction with glucose metabolism and autophagic degradation were also illustrated. Possible molecules that regulate the Let-7 homeostasis in between non-carbohydrate metabolism and autophagy processes were indicated.

\subsection{GLUT12}

As reported, tumor cells tend to switch carbohydrate metabolism by changing the method of glucose uptake and the modulation of glucose transporters. According to the findings of Shi et al., the expression of glucose transporters (GLUT) 12 is associated to the poor prognosis in triple-negative breast tumors and negatively to the expression of Let-7a. Experimental assays have further demonstrated that Let-7a modulates GLUT12-mediated tumor growth and motility by targeting 3'UTR of GLUT12. Additionally, Let-7a-suppressed mitochondria respiration can be rescued by overexpression of GLUT12 [23].

\section{2. $H K 2$}

Jian et al. analyzed the Let-7 cluster function in terms of immunoglobulin production in B cells through a serial mouse genetic manipulation model. They found that Let-7a/d/f regulates glycolysis by inhibiting Hexokinase-2 (HK2) and modulates glutamine uptake by suppressing the glutamine transporter (Solute Carrier Family 1 Member 5, Slc1a5) axis, as well as glutaminase (Gls) via c-Myc, to restrict the tricarboxylic acid cycle (TCA cycle), consequently changing the ability of B cells to produce specific IgM [61]. As classified in the Let-7 family, the miR-98 has been identified as having lower expression in colon cancer tissue compared to normal tissue. The conducted two-way model revealed that miR-98 was participated to cells' proliferation ability. Consistent with Let-7a functions, the production of lactate and mitochondria respiration can be inhibited by targeting 3'UTR of HK2 to inhibit tumor growth [62]. A similar phenomenon was observed, MiR-98 targets the 3'UTR of MAP kinase phosphatase 1 (MKP1) to modulate mitochondria respiration in nonsmall-cell lung cancer, although the evidence of how MKP1 regulates glycolysis remains insufficient [63]. MiR-202, another Let-7 member, has also been demonstrated by Deng et al.'s group to target HK2 by a similar approach. They revealed that the expression of $m i R-$ 202 was decreased in chronic myeloid leukemia cells, and an increase of the miR-202 level inhibited cell proliferation ability. In imatinib-resistant cells with high glycolysis activity, overexpression of $m i R-202$ increased imatinib sensitivity by restricting the expression of HK2, GLUT1, and lactate dehydrogenase A (LDHA) [64].

The relatively low level of Let-7 expressed in a variety of cancers may explain the role of those Let-7 downstream molecules in the regulation of drug resistance. Inhibition of Let-7 has usually been observed in drug-resistant cells $[65,66]$. Li et al. found that Let-7i was decreased in cisplatin-resistant lung cancer cells [67], consistent with the related expression of miR-202, which was negatively correlated with imatinib-resistant ability [64]. Several essential enzymes of glycolysis—including HK2, pyruvate kinase M1/2 (PKM1/2), GLUT1, and LDHA-were increased in the cisplatin-based resistant cell model [65]. The events of miR-202 targeting HK2 were consistently reported in hepatocellular carcinoma and pancreatic cancer $[43,59]$.

\subsection{ALDOC}

Common metabolic-related diseases such as diabetes have been reported to be correlated with cancer progression. Studies have identified that the distribution of BCDIN3 Domain Containing RNA Methyltransferase (BCDIN3D), a RNA methylate in type II diabetes, is correlated with breast cancer prognosis. Knockdown BCDIN3D suppresses breast cancer growth by modulating mitochondrial respiration. RNA-seq and proteomics-based profiling showed that BCDIN3D-dominant mTOR signaling regulates glucose-related enzymes. Aldolase C (ALDOC) results in fructose 1,6 bisphosphate (F1,6BP) intermediate accumulation. Mechanistically, BCDIN3D regulates ALDOC via the Let-7 family, including Let-7b, Let-7d, Let-7e, Let-7f, Let-7g, Let-7i, and miR-98 [68]. ALDOB/C has been reported to 
be involved in fructolysis [69], indicating that Let-7 may regulate the noncarbohydrate carbon substrates metabolism pathway to control mitochondria-related glucose metabolism.

\subsection{PKM2}

Increasing the level of Let-7 accelerates mitochondrial activity by increasing the membrane potential, oxygen consumption rate, and extracellular acidification rate, which changes the method of glucose metabolism by disturbing the aerobic glycolysis (the Warburg effect) of cancer cells. Although an accelerating rate of glucose uptake and upregulated activity of pyruvate kinase M2 (PKM2) can be observed in Let-7-overexpressing cells, the Warburg effect is no longer the primary processes of glucose metabolism in cancer cells [15]. Instead of aerobic glycolysis, cells have started to use oxidative phosphorylation and have consequently increased the related level of reactive oxygen species (ROS) in the mitochondria. Accumulated ROS under switched metabolism makes cells increase their oxidative response in response to therapeutic drugs. In addition, it has been speculated that the morphology change of cells is related to ROS-mediated anaerobic glycolysis, which involves the epithelial-to-mesenchymal transition [15]. However, further investigations are required to find out whether Let-7 serves as a key to switch oxidative phosphorylation to the Warburg effect and thereby promotes cell malignancy. Notably, the overexpression of PKM2 has been identified as positively correlated with malignancy and poor prognosis in breast cancer. The knockdown of PKM2 inhibited the proliferation of breast cancer [70,71], thus indicating that Let-7-modulated PKM2 activity might be associated with the conversion of the original glucose metabolism pathway into cancer-favoring metabolic processes and sustained tumor malignancy.

Yao et al. provided evidence that an increase in Let-7a inhibited the expression of PKM2 as well as GLUT1 and Phosphofructokinase-1 (PFK1) in breast cancer [72]. A similar phenomenon was observed in glioma by Luan et al., who found that Let-7a restricts PKM2-mediated aerobic glycolysis and cell growth. Mechanistically, Let-7a suppresses Myc by targeting its $3^{\prime}$ UTR to block the downstream heterogeneous nuclear ribonucleoprotein A1 (HnRNPA1)/PKM2 axis. HnRNPA1 forms a terminal loop with Let-7a by inhibiting its essential biogenesis factor, Drosha, to maintain the level of pri-Let-7a in glioma [73]. Such a regulation circuit may explain why Let-7 expression is inhibited upon biogenesis during carcinogenesis, resulting in cells switching the oxidative phosphorylation into the Warburg effect. Despite the fact that the tumor suppressor role of Let-7 has been demonstrated in breast cancer and glioma, with controversial responses in terms of mitochondria respiration [15,73], the evidence suggests that Let-7 may regulate the diverse activity of glucose metabolism-related enzymes to control tumoral functions. Biologically, Let-7a suppresses the Myc/HnRNPA1/PKM axis, which further modulates tumor growth and motility [74]. The regulation of the Let-7/Myc axis has also occurred in B-cells, and this Let-7-mediated regulation has been demonstrated to regulate glycolysis and glutamine uptake [61].

\subsection{Noncarbohydrate Metabolism Crosstalk}

Let-7 has been considered a terminal differentiation factor and participates in postnatal cardiac maturation by switching glycolysis and fatty acid oxidation under limited glucose resources through the Let-7g-and Let-7i-mediated PI3K/AKT/insulin axis [75]. Additionally, gluconeogenesis, as an inverse glucose metabolism pathway, has been observed to be regulated by Let-7. Recently, Methyltransferase 3, N6-Adenosine-Methyltransferase Complex Catalytic Subunit (METTL3) has been reported to be associated with a poor prognosis of hepatocellular carcinoma. A gene set enrichment analysis revealed that METTL3 is correlated with glycolysis and gluconeogenesis-related enzyme levels. Knockdown of METTL3 decreases glucose uptake, consequently suppressing lactate production by altering the Warburg effect. Within this route, mTOR signaling is also suppressed by the downregulation of METTL3 [76]. METTL3 has been demonstrated to be a Let-7g-specific target in breast cancer. Let-7g-mediated METTL3 has been found to be negatively regulated by HBXIP to promote tumor growth. It participates in the feedback loops of the HBXIP/METTL3 
axis by N6-methyladenosine modification and regulates glucose metabolism in breast cancer [77]. Apart from this, a high level of polyamines has been reported to contribute to cancer progression. The crosstalk between polyamine and glucose metabolism can be suppressed by 2-deoxy-d-glucose treatments [78]. In colorectal cancer, treating cells with difluoromethylornithine suppresses polyamines levels-including putrescine, spermidine, and spermine-and induces Let-7i expression. However, decreased polyamines, resulting in a downstream eIF5A1/A2 and LIN28 axis, were not able to suppress Let-7i expression in neuroblastoma [10]. This is connected to the role of Myc, a downstream target of Let-7 that regulates protein synthesis, glycolysis, and polyamine synthesis. Notably, eIF5A1 was associated with protein synthesis, and such a regulation may link the Let-7-mediated metabolism regulation circuit between glucose and noncarbohydrates.

\subsection{Oxidative Stress}

Several genes related to energy metabolism-including MT1X, MT2A, MT1G, MT1A, SOD2, TXNRD1, GSTM3, CTH, HMOX1, and FTH1-have been reported to be associated with oxidative stress and regulated by Let-7a. Under hypoxia, HIF-1 $\alpha$ was activated, promoting glucose metabolism and increasing tumor stemness [79]. Glycolysis-related enzymes, such as ALDOA with nonenzymatic functions, positively regulate the HIF$1 \alpha /$ ALDOA feedback loops to increase the activation of MMP9 in lung cancer under hypoxia [80]. Knockdown of carbonic anhydrase IX, a factor upregulated under hypoxia conditions, transactivates Let-7d, Let-7c, and Let-7f to suppress LIN28 as well as pyruvate dehydrogenase kinase 1 (PDK1) expression, leading to decreased tumor stemness activity [81].

\subsection{Stemness Activity}

Cai et al. identified that the stemness of breast cancer was controlled by the Wnt/ $\beta$ catenin-mediated repression of the Let-7 family. The decreased level of Let-7 was regulated through the activation of Lin28. The involvement of the Let-7/Lin28 axis in the Wnt/ $\beta$-catenin pathway was primarily found in breast cancer [82]. Their group further identified Chibby as a primary transcription factor of Wnt signaling, negatively regulating the expression of $\beta$-catenin in nasopharyngeal carcinoma. The clinical relevance of the expression level between $\beta$-catenin and Chibby in nasopharyngeal carcinoma was negatively correlated. Increased Chibby induces cells to switch the Warburg effect into oxidative phosphorylation to change ATP production, initiating oxygen consumption and lactate release. Mechanistically, Chibby suppresses Wnt/ $\beta$-catenin/PDK1/Lin28/Let-7g to control tumor proliferation [83].

\subsection{Compound-Related Regulators}

Recently, several reports have revealed that Let-7-mediated glucose metabolism could be affected by specific compounds. Alharris et al. found that, by treating cells with phytocannabinoid-related molecules, cannabidiol can suppress Let-7a to modulate metabolism pathways and related downstream effectors, including GAS7 and CASP3, subsequently inducing apoptosis to suppress neuroblastoma progression [84]. Dichloroacetate was designed to change pyruvate dehydrogenase activity, which leads glucose metabolic intermediates into the TCA cycle to execute oxidative phosphorylation in mitochondria. Treating cancer cells with dichloroacetate decreases glucose metabolism and cell viability. Interestingly, it was observed that Let-7 $a$ and Let-7c could be transactivated by dichloroacetate in the breast cancer cell line MDA-MB-231 [85]. Overexpression of Let-7 mimics the effects of dichloroacetate treatment on the induction of Bax/P53 cascade, increasing the expression of proliferator-activated receptor gamma co-activator 1 alpha (PGC1 $\alpha$ ) and Mitofusin 2 (MFN2) to accelerate mitochondria fusion and the release of ROS from oxidative phosphorylation, leading to apoptosis [85]. Although the effect of PGC1 $\alpha$ and MFN2 on the Warburg effect remains unclear, these results suggest that Let-7 could regulate glucose metabolism and tumor cells could switch glucose metabolism into the Warburg effect in the 
way of this Let-7-associated modification. In addition, Let-7 could affect mitochondria stability by oxidative phosphorylation. RNA-seq profiling of rectal carcinoma from Chen et al. showed that Let-7e was correlated with the expression of peroxisome proliferator-activated receptor coactivator 1 alpha (PGC-1alpha) and mitochondrial biogenesis molecules, and may contribute to liver metastasis [86]. Similar observations were described by Xu et al., who described that ATP5A1 and ATP5B increased while Let-7f decreased in glioblastoma. A simulated analysis showed that Let- $7 f$ regulates oxidative photophosphorylation through the regulation of ATP5B [87].

\section{Let-7-Mediated Autophagy Participates in Glucose Metabolism and \\ Cancer Progression}

\subsection{Let-7 and Autophagy}

In lung cancer, Let-7 targets IGF-1R to induce autophagy and blocks the function of BCL2L1/BCL2/PI3K complex to induce apoptosis and pyroptosis and inhibit cell motility [88]. Let-7a targets Rictor's mTORC2 component, inhibiting AKT/mTORC1 signaling to activate autophagy in gastric cancer [89]. Similar regulation can be observed in human placental trophoblasts, in which the expression of Let-7b was correlated with cell growth and motility. The Let-7b-mediated TGFBR1/ERK/IL-6/TNF- $\alpha$ cascade triggers not only apoptosis but also autophagy. Such regulation may contribute to pre-eclampsia during pregnancy [90]. In glioma, the downregulation of STAT3 was mediated by Let-7a, Let-7d, and Let-7f. Upregulation of Let-7 suppressed the expression of STAT3, resulting in the inhibition of cell proliferation and induction of autophagy and apoptosis [91]. Liang et al. identified that a set of the Let-7 family was downregulated in hepatocellular carcinoma, with different clinical correlations under a genetic profiling analysis. The expression of Let-7b and Let-7c had a better prognosis; Let-7e had a poor prognosis instead. Among them, Let-7e has been demonstrated to promote tumor growth by suppressing autophagy and apoptosis [92]. A similar strategy was used in cholangiocarcinoma. Clinical evidence showed that the expression of NUAK1 was negatively correlated with Let-7a. NUAK1mediated cholangiocarcinoma cell motility can be suppressed by increasing Let-7a. In turn, the overexpression of Let-7a inhibited NUAK1-mediated tumor malignancy by the induction of autophagy [93]. Additionally, Let-7 can be regulated by LncRNA H19 and LIN28 in breast cancer. The expression of long non-coding RNA (lncRNA) H19 and LIN28 was correlated with breast cancer's poor prognosis and metastasis ability. Overexpression of H19 and LIN28 increases the expression of several autophagy-related ATG markers as well as its puncta structure formation. Downregulation of Let-7 increased the transcript activity of several EMT-related genes-including Slug, Zeb1, Twist, Snail, $\beta$-catenin, and HMGA2 - to modulate the metastasis of breast cancer [94]. Another lncRNA MIR99AHG, as well as its Let-7c-associated cluster, were reported to have decreased expression in lung cancer. MIR99AHG increased Let-7c, subsequently promoting autophagy via targeting mTOR, an autophagy suppressor of nucleation, and ANXA2, a negative regulator of elongation, to suppress the growth and motility of lung adenocarcinoma [95]. In view of the controversial role of autophagy in a variety of cancers, the regulation of Let-7-mediated autophagy in tumor progression could be complicated-and condition-, environment-, and tissue-specific.

\subsection{Autophagy Activators}

Several components have been identified as triggering Let-7-mediated autophagy in cancer cells. Treating cells with recombinant capsid protein viral particle 1 (rVP1) induces autophagy to regulate the motility of macrophages [96] and ovarian cancer cells [97]. In ovarian cancer, autophagy - activated by either a canonical or a rVP1-mediated noncanonical pathway-maintains the homeostasis of the Let-7 level through SQSTM1-mediated degradation of Dicer/AGO2 inhibition of cell migration [97]. In lymphosarcoma, the expression of Let-7g/CTSB may be suppressed by ribonuclease binase to participate in apoptosis and autophagy [98]. 


\subsection{Drug Resistance}

In gastric cancer, the expression of $m i R-202$ can be restricted by lncRNA MALAT1, resulting in the activation of autophagy, increased tumor malignancy, and an enhanced drug-resistant ability [99]. In agreement with other reports, Yang et al. showed that paclitaxel-based drug-resistant breast cancer cells express a high level of CircRNA ABCB10 and autophagy, which are correlated with clinical paclitaxel-sensitive or resistant data and negatively associated to Let-7a. Mechanistically, the Let-7a/DUSP7 axis is a downstream effector of Circ-ABCB10 resistant to paclitaxel treatment. Knockdown of Circ-ABCB10 not only increases sensitivity to paclitaxel but also decreases tumor weight [100]. Similar regulation was observed in a cisplatin-based resistance model of A549 with a high level of DICER. Overexpression of DICER induces autophagy processes and increased tumor growth and motility, in which DICER-mediated suppression of Let-7i and the PI3K/AKT/mTOR axis contributes to the autophagy activity [67]. In medulloblastoma, inhibited autophagy was found to promote tumor resistance upon cisplatin treatment. The level of Let-7f in cells was insufficient to repress HMGB1 and led to autophagy-mediated drug resistance. Overexpression of Let-7f could attenuate cisplatin's drug resistance and induce apoptosis in medulloblastoma cells [101].

\subsection{Let-7-Mediated Autophagy in Glucose Metabolism}

Recently, Let-7-mediated autophagy has been described as participating in glucose metabolism events. For example, Duan et al. observed that Let-7 targeted BCL-xL to induce autophagic cell death in lung cancer, indicating that Let-7 regulates mitochondria-related autophagy (mitophagy) to regulate metabolism-related events, and BCL-xL with nonapoptotic functions to induce cell death [102]. However, the underlying mechanism of Let7-mediated autophagy in glucose metabolism that contributes to cell stress and death needs to be further elucidated. According to the above reports, several links may support the correlation between Let-7, autophagy, and glucose metabolism. In turn, Lai et al. found that-in a hypoxic environment-HIF- $1 \alpha$ can interact with DICER to regulate miRNA processing in diverse cancer types, including colon, breast, liver, lung, and prostate cancer [103]. HIF-1 $\alpha$ changed the glycolysis-related enzyme PDK1 level and induced autophagy-mediated proteolysis by interacting with Parkin/p62 to possess DICER, which decreased Let-7 biogenesis. Overexpression of HIF- $1 \alpha$ reduced the levels of Let-7a, Let-7b, and Let-7d as well as its complement downstream target LIN41 and Aurora B to promote tumor metastasis [103]. However, how glycolysis participates in DICER ubiquitination and related autophagy processes has not yet been well explained. So far, Lai et al.'s study provides a possible reason for why the Let-7 level being downregulated under hypoxia is an important factor contributing to tumor microenvironment reprogramming and providing tumor cells with escape from immune surveillance. Recently, bone marrow-derived human mesenchymal stem cells (hMSCs) have been observed to have anticancer activity. Egea et al. found that Let-7f can be transactivated under hypoxia to induce autophagy in hMSCs and promote migration in tumor cells [104]. Let-7f can be regulated by TGF- $\beta$, TNF- $\alpha$, IL-1 $\beta$, and SDF- $1 \alpha$ to modulate CXCR4 and MMP-9 expression and drive chemotactic invasion. Interestingly, hMSCs have been observed to transport Let-7f by exosome secretion to inhibit the growth and motility of breast cancer; such events can be reversed with the Let-7f inhibitor [104].

\section{5. mTOR-Dependent Autophagy and Glucose Metabolism}

Several studies have found that Let-7 mediates glucose metabolism through the regulation of mammalian target of rapamycin (mTOR) [67,68,76,89]. It is also a well-known negative regulator of autophagy. Notably, human growth hormone receptors (GHR) have played an essential role in glucose metabolism and are linked to mTOR activity. A murine model revealed that, under limited nutrients, growth hormone maintained the cellular glucose level through gluconeogenesis, accompanied by the induction of autophagy [105]. In addition, GHR has been identified to contribute to breast and prostate cancer malignancy $[106,107]$. Elzein et al. reported that GHR is the target of miR-202. Increased miR-202 
suppresses the expression of GHR in MCF and LNCaP cells [108]. Additionally, it has been reported that PKM2 and $\mathrm{mTOR}$ expression is downregulated under glucose restriction in breast cancer, which reverses the Warburg effect of cells [109]. Strikingly, these molecules were all be Let-7 downstream effectors. Such regulation may explain how Let-7 mediates autophagy and glucose metabolism to regulate cancer cell progression (Figure 1).

\section{Possible Connections between Let-7-Mediated Glycolysis and Autophagy in Cancer Progression}

According to the literature review, we separately discussed the link of the Let-7 family to glucose metabolism and autophagy. The intermediates of noncarbohydrate metabolisms, such as amino acids and lipids, are also integrated into glucose metabolism and regulated by Let-7 [61,75]. Our aim in this section is to profile a more comprehensive linkage between autophagy and glucose metabolism via Let-7 regulation. We conducted a molecular regulation network simulation, including the upstream regulators and downstream effectors of the Let-7 family. Table 3 lists the upstream regulators and downstream effectors of the Let-7 family involved in autophagy and metabolism-related biological events. Moreover, according to the literature review, the Let-7 family may be involved in glycolysis- and autophagyrelated tumorigenesis, so simulated results of relative upstream regulators/downstream effectors are briefly displayed (Figure 1). Possible effects/mediators/molecules of the relationship between glucose metabolism and autophagy, and connecting networks, are also discussed.

Table 3. Simulated results profiling of Let-7 regulators, linked to autophagy and glucose metabolism. All molecules related to the Let-7 family were downloaded from the ENCORI database (https: / / starbase.sysu.edu.cn/index.php, accessed on 20 September 2021) and processed using Ingenuity Pathway Analysis (https: / / analysis.ingenuity.com, accessed on 20 September 2021) to link to the possible molecular regulations.

\begin{tabular}{|c|c|c|c|c|c|c|c|}
\hline & \multicolumn{7}{|c|}{ Upstream Regulators } \\
\hline $\begin{array}{c}\text { Let-7 } \\
\text { Regulators }\end{array}$ & \multicolumn{7}{|c|}{ LIN28, AKT, AP1, CREB, E2F1, FOXO1, FOXO3, HIF-1 $\alpha$, Myc, NF-кB } \\
\hline \multirow[t]{2}{*}{ Reference } & \multicolumn{7}{|c|}{ [110-126] } \\
\hline & \multicolumn{7}{|c|}{ Downstream Regulators } \\
\hline \multirow[b]{2}{*}{$\begin{array}{l}\text { Let-7 } \\
\text { family }\end{array}$} & Glycolysis & TCA cycle & Glutamine & Arginine & Autophagy & $\begin{array}{l}\text { Oxidative } \\
\text { stress }\end{array}$ & $\begin{array}{l}\text { Mitochondria } \\
\text { stability }\end{array}$ \\
\hline & ALDOC, PGK1 & $\begin{array}{c}\text { Citrate synthase, } \\
\text { Malate } \\
\text { dehydrogenase }\end{array}$ & Glutaminase & Arginase & AMPK & $\begin{array}{c}\text { HIF-1 } \alpha, \\
\text { Glutathione } \\
\text { peroxidases }\end{array}$ & $\begin{array}{c}\text { Monoamine } \\
\text { oxidase A }\end{array}$ \\
\hline Reference & {$[68,83,127-134]$} & [135-137] & {$[61,138-143]$} & [144-149] & [150-152] & {$[80,103,153]$} & [154-156] \\
\hline
\end{tabular}

\subsection{Upstream Regulators}

\subsubsection{LIN28}

Several Let-7 upstream regulators have been identified. The most well-known factor is LIN28. Zhou et al. observed that LIN28B affects diverse metabolism-related gene ontology, including the metabolism of cellular amino acids, oxoacids, organic acids, and carboxylic acid. LIN28B regulates IGF2BP1 via Let-7a or Let-7b to affect acute myeloid leukemia cell proliferation [110]. However, no direct evidence clarifies the link between Let-7 and metabolic processes. Similar observations were described by Ackermann, who showed that the balance between Let-7 and LIN28B can be controlled by C/EBP $\beta$-LIP. Using mouse embryonic fibroblasts as a cancer metabolic reprogramming mimic model, their study indicated that $C / E B P \beta$-LIP changed the mitochondrial respiration and served as a transcription factor to regulate the Let-7 family-including Let-7a, Let-7b, Let-7c, Let-7d, 
Let-7f, Let-7g, and Let-7i-consequently modulating cell glycolysis, proliferation, tissue regeneration, and carcinogenesis [111].

The simulation of upstream regulators of Let-7-including AKT, AP1, CREB, E2F1, FOXO1, FOXO3, HIF-1 $\alpha$, Myc, and NF- $\mathrm{B}$ - contributed to autophagy-related biological features. When cells are stimulated with toxins, metabolic stresses, ischemia, trauma, and inflammation trigger metabolic reprogramming in the mitochondria and ER, causing DNA damage and activating autophagy [112].

\subsubsection{AKT}

Usually, with adequate nutrition, autophagy activity is suppressed by PI3K/AKT/mTOR signaling, which blocks the ULK complex (ULK1/2, FIP200, and ATG13) in autophagy initiation. Once in starvation conditions, autophagy is activated inversely [113]. In gastric cancer, AKT is activated by NEK2 to regulate cell proliferation. Phosphorylated AKT promotes cell switching to aerobic glycolysis, accompanied by increased glucose uptake and lactate production. Notably, increased NEK2 suppresses autophagy through the $\mathrm{AKT} / \mathrm{mTOR}$ axis, and, by treating AKT-specific inhibitors, induces autophagy and reverses mitochondrial respiration by inhibiting GLUT1, PKM2, and HIF-1 $\alpha$ [114]. A similar observation has been made in prostate cancer. AKT activity is inhibited by FGF21 and blocks mTOR signaling to drive autophagy [115]. AKT has been demonstrated to regulate Let-7 to change glucose metabolism. In type II diabetes patients, the Let-7 level is controlled by insulin/PI3K/AKT to govern glucose uptake in muscle cells [116]. This relationship indicates that the tumor suppressor Let-7 expression could be dysregulated and may influence autophagy in the regulation of cell death or survival. These studies explain how diabetes is linked to cancer progression within Let-7/glycolysis/autophagy regulation.

\subsubsection{NF-кB}

As a downstream factor of $\mathrm{AKT}, \mathrm{NF}-\mathrm{\kappa B}$ has been demonstrated to regulate the Let-7 family-including Let-7a, Let-7b, Let-7f, and Let-7g-by inhibiting LIN28B in castrationresistant prostate cancer [117]. However, no direct evidence shows that NF- $\mathrm{BB}-\mathrm{mediated}$ Let-7 participates in autophagy processes. Liang et al. observed that treating cells with galangin inhibits NF-KB signaling from activating autophagy in gastric cancer [118].

\subsubsection{FOXO}

FOXO is associated with glucose and lipid metabolic processes [119]. The activity of FOXO can be regulated by insulin/AKT, and then translocates into the nucleus as a transcription factor [120]. In cancer, FOXO1 was activated by ROS to regulate autophagy and mitochondrial oxidative metabolism [121,122]. In breast cancer, the level of FOXO3 can be induced by rapamycin, AZD3463, and AZD-RAPA, accompanied by autophagy formation [123]. Hopkins' group reported that FOXO3 could be regulated by peroxidase peroxiredoxin 1 to control Let-7b and Let-7c, affecting cell migration ability. Notably, the activity of FOXO3 is partially regulated by AKT [124].

\subsubsection{Myc}

Myc is the Let-7 downstream target, and Myc can regulate Let-7 by LIN28 [125]. Interestingly, treating cells with aristolochic acid I can activate Myc and NF- $\mathrm{B}$ to control the LIN28B/Let-7b axis, activating FOXO1 to promote tumorigenesis and resistance to apoptosis [126]. However, how AP1, CREB, and E2F1 regulate Let-7 has not been reported.

\subsection{Glycolysis}

The downstream molecules/regulators of Let-7 family are discussed in this section. ALDOC and phosphoglycerate kinase (PGK1) have been identified as possible downstream targets of Let-7 (Table 3). Aldolases are an essential enzyme of gluconeogenesis in regulation of converting Fructose 1,6-Bisphosphate (F1,6BP) into dihydroxyacetone phosphate (DHAP) and glyceraldehyde 3-phosphate (G3P). In breast cancer, ALDOC can be regulated by Let-7f 
and contributes to type II diabetes-mediated breast cancer [68]. PGK1 has been observed to be correlated with poor prognosis of glioblastoma [127] and has been demonstrated to bind directly to the Beclin1 and ATG14, two ATGs required for the autophagy process [127,128]. Mechanistically, PGK1 can phosphorylate Beclin1 and promote phagophore formation, resulting in the induction of autophagy and tumor malignancy. Notably, such regulation is involved in glutamine deprivation events [127]. Even though no direct evidence clarifies the link between Let-7 and PGK1, as reported, PGK1 is a critical mediator for AKT/mTOR signaling, which may link to autophagy activity $[129,130]$. Together with the identified upstream regulators of Let-7, AKT may serve as a link between PGK1 and Let-7. This evidence links Let-7-mediated autophagy to glucose metabolism, and the crosstalk of amino acid metabolism mediated by ALDOC and PGK1. Another similar postulation can be raised for Let-7 and PKG1. PGK1 and HIF-1 $\alpha$ can form a regulatory circuit for controlling breast cancer metastasis [131]. Additionally, Myc serves as an upstream regulator of Let-7 (Table 3), while PGK1 is a downstream target of Myc [132-134]. The Let-7 might function as a linker for Myc to carry out post-transcriptional modification on PGK1, given the possible connection between PKG1 and Let-7.

\subsection{TCA Cycle}

Citrate synthase activates AKT, Let-7's upstream regulator, to modulate metastatic progression of triple-negative breast cancer [135]. Berberine has been reported to decrease the expression of citrate synthase in mitochondria, triggering autophagy and apoptosis in glioblastoma and pancreatic cancer cells [136]. Malate dehydrogenase is a novel autophagy regulator that has been identified in pancreatic ductal adenocarcinoma. Activation of malate dehydrogenase maintains the ULK1 level and improves resistance to starvation and hypoxia conditions. Interestingly, the activation of autophagy can induce the expression of malate dehydrogenase [137]. However, how PGK1, citrate synthase, and malate dehydrogenase are regulated by Let-7 has not been fully investigated. The simulated results are provided, and the potent Let-7 downstream molecules including citrate synthase and malate dehydrogenase that may be involved in autophagy regulation are documented in Table 3.

\subsection{Glutamine}

Glutaminase is an essential enzyme that can convert glutamine to glutamate. In Bcells, Let-7 regulates glutaminase by Myc, consequently blocking glutamate conversion to $\alpha$-ketoglutarate $(\alpha-\mathrm{KG})$ during the TCA cycle, which is related to IgM production in $B$-cells [61]. In cancer, the glutaminase level is correlated with colorectal tumor progression. Decreased glutaminase induces oxidative stress and inhibits autophagy formation by suppressing tumor growth and motility [138]. Mukha and his group identified that the glutamine level is correlated with radiosensitivity of prostate cancer. A global gene expression profiling metabolism signature shows radioresistant cells with high-level glutamine and $\alpha-K G$ in radioresistant PC-3 and DU145. Block supplies of glutamine or glutaminase induce radiosensitivity and trigger the autophagy progress [139]. Interestingly, $\alpha-K G$ has been observed to contribute to tumor stemness activity through JMJC-mediated histone demethylation [140]. A similar study, reported by Xia et al., showed that genetic modification, such as KRAS mutation, has different glucose and glutamine metabolic profiles. Treating cells with a glutaminase inhibitor can change the mitochondrial membrane potential to induce ROS production while decreasing AKT activity, and leads to activation of autophagy. A combination KRAS and glutaminase inhibitor had a synergistic effect on antitumor progression [141]. Mitochondrial damage and oxidative stress can trigger autophagy to remove damaged organelles and reduce oxidative pressure to decrease cytotoxicity. Selenium has been demonstrated to inhibit glutaminase and promote ROS levels to induce autophagy and apoptosis in lung cancer $[142,143]$. To sum up the evidence, Let-7 inducing ROS levels or targeting the TCA cycle could be proposed as alternative strategies to control tumor progression in an autophagy-associated manner. 


\subsection{Arginine}

In non-carbohydrate metabolism, arginase is an essential enzyme for arginine conversion to ornithine and glutamate by the urea cycle, which is crucial for the TCA cycle. Arginase is considered an essential marker in cancer [144-146] and may be targeted by Let-7 (Table 3). Genetically modified mouse models show that the deletion of ATG5 or ATG7 induces an increase in the level of arginase 1 in serum, decreasing the circulating arginine and increasing the ornithine level to depress tumor growth [147]. Modified arginase 1 can reduce arginine levels and induce autophagy or apoptosis in colon cancer [148]. In the tumor microenvironment, arginase increased in Tim $4^{+}$Tumor-associated macrophages and was associated with mitochondrial respiration and autophagy (mitophagy). Genetically modified mouse models show that the deletion of FIP200 can inhibit autophagy and decrease the Tim $4^{+}$Tumor-associated macrophage population, consequently promoting the antitumor activity of T-cells [149].

\subsection{Autophagy Processes}

Stress-mediated $5^{\prime}$ adenosine monophosphate-activated protein kinase (AMPK) is known to activate the ULK complex, and its activity has been correlated with the glucose level [150]. Simulated results reveal that the Let-7 family may contribute to AMPK expression. Recently, there has been evidence that the expression of Let-7 is linked to glucose metabolism and insulin levels during pregnancy. Furthermore, Let-7-mediated AMPK contributes to liver metabolism [151]. Additionally, Zhong et al. revealed that one diabetes-related drug, metformin, increases AMPL activity and Let-7 to regulate gene methylation in ARK2 and MCF-7 cells [152]. Moreover, simulated results show that the autophagy-related components might be regulated by Let-7 (Table 3).

\subsection{Oxidative Stress}

Oxidative stress such as hypoxia is ubiquitous in tumors and the microenvironment. As an oxidative stress factors, HIF- $1 \alpha$-mediated Let-7 participates in autophagy, and glucose metabolism has been reported [103]. In lung cancer, activated HIF1 $\alpha$ is a transcription factor that transactivates ALDOA and promotes the Warburg effect, increasing lactate production under hypoxia. Interestingly, lactate, in turn, negatively regulates hypoxia-inducible factor 1 alpha and stabilizes HIF-1 $\alpha$, which forms a regulatory circuit to increase cell motility [80]. In addition, HIF- $1 \alpha$ can modulate Let-7a, Let-7b, and Let-7 $d$ biogenesis by interacting with DICER to activate PDK1 [103]. The production of excess reactive oxygen species (ROS) is harmful for cells metabolism and usually leads to cells damage. ROS can be removed by glutathione and may be targeted by Let-7 as predicted (Table 3). Increases in glutathione peroxidases (GPX) are observed in acute myeloid leukemia, including GPX1, GPX4, and GPX7. GPX1 and GPX4 have been demonstrated to be decreased by miR-202 to regulate mitochondria stability [153].

\subsection{Mitochondria Stability}

Additionally, mitochondria stability-related proteins, such as monoamine oxidase A, may be linked to Let-7 as well. In gastric cancer, monoamine oxidase A is correlated with poor prognosis. Knockdown of monoamine oxidase A suppresses mitochondria respiration and glycolysis [154]. Similar results can be observed in lung cancer. Monoamine oxidase A has a positive to poor prognosis and can promote aerobic glycolysis through HK2 [155]. In prostate cancer, increased monoamine oxidase A induces ROS-mediated apoptosis under androgen deprivation [156].

\section{Conclusions}

Even though Let-7 was the first miRNA identified, its related biological functions linked to diverse biological processes, including glycolysis and autophagy, remain obscure. In this review, we performed a literature review and omics data analysis to generate simulated results to elucidate how Let-7-mediated autophagy participates in glucose metabolism, 
revealing possible molecules that may participate in this regulatory network. However, the related processes may differ from different genetic backgrounds, cancer types, and therapeutic strategies. Mainly, nutrient uptake is the primary means of maintaining fundamental cellular functions. Directly targeting the Let-7 family to improve the imbalance in nutrient metabolism in cancer cells and minimize the side effects caused by intense treatment is challenging. Therefore, we provide a comprehensive review and detail the regulations and connections between the Let-7-family-related glycolysis and autophagy in cancer progression.

Author Contributions: Draft and figures preparations: C.-H.L. Manuscript revisions and corrections: C.-H.L. and C.-C.L. Study supervision: C.-C.L. All authors have read and agreed to the published version of the manuscript.

Funding: This work was financially supported of the Higher Education Sprout Project (110AC-P403) by the Ministry of Education (MOE) in Taiwan.

Institutional Review Board Statement: Not applicable.

Informed Consent Statement: Not applicable.

Data Availability Statement: To perform the simulated molecular interaction model of the Let-7 family, the related up-regulators and downstream effectors were downloaded from ENCORI database (https:/ / starbase.sysu.edu.cn/index.php, accessed on 20 September 2021), then subjected these molecules to the Ingenuity pathway analysis (IPA) (https:/ / analysis.ingenuity.com, accessed on 20 September 2021) to generate the related graphical summary, canonical pathway, and upstream regulators.

Conflicts of Interest: The authors declare no conflict of interest.

\begin{abstract}
Abbreviations
miRNA, microRNA; G6PD, Glucose-6-phosphate Dehydrogenase; IMPDH2, Inosine5'-monophosphate dehydrogenase 2; FASN, Fatty Acid Synthase; AASDHPPT, AminoadipateSemialdehyde Dehydrogenase-Phosphopantetheinyl Transferase; GLUT, glucose transporters; HK2, Hexokinase-2; Slc1a5, Solute Carrier Family 1 Member 5; Gls, glutaminase; TCA, tricarboxylic acid; MKP1, MAP kinase phosphatase 1; LDHA, lactate dehydrogenase A; PKM1/2, pyruvate kinase M1/2; BCDIN3D, BCDIN3 Domain Containing RNA Methyltransferase; ALDOC, Aldolase C; F1,6BP, fructose 1,6 bisphosphate; PKM2, pyruvate kinase M2; PFK1, Phosphofructokinase-1; HnRNPA1, heterogeneous nuclear ribonucleoprotein A1; METTL3, Methyltransferase 3, N6-AdenosineMethyltransferase Complex Catalytic Subunit; PDK1, dehydrogenase kinase 1; PGC1 $\alpha$, gamma co-activator 1 alpha; MFN2, Mitofusin 2; PGC-1alpha, peroxisome proliferator-activated receptor coactivator 1 alpha; IncRNA, long non-coding RNA; rVP1, recombinant capsid protein viral particle 1 ; GHR, growth hormone receptors; PGK1, phosphoglycerate kinase; F1,6BP, Fructose 1,6-Bisphosphate; DHAP, dihydroxyacetone phosphate; G3P, glyceraldehyde 3-phosphate; $\alpha-K G, \alpha$-ketoglutarate; AMPK, 5' adenosine monophosphate-activated protein kinase; ROS, reactive oxygen species; GPX, glutathione peroxidases; hMSCs, human mesenchymal stem cells.
\end{abstract}

\title{
References
}

1. Zhu, J.; Thompson, C.B. Met abolic regulation of cell growth and proliferation. Nat. Rev. Mol. Cell Biol. 2019, 20, 436-450. [CrossRef] [PubMed]

2. Lahiri, V.; Hawkins, W.D.; Klionsky, D.J. Watch What You (Self-) Eat: Autophagic Mechanisms that Modulate Metabolism. Cell Metab. 2019, 29, 803-826. [CrossRef]

3. Michlewski, G.; Caceres, J.F. Post-transcriptional control of miRNA biogenesis. RNA 2019, 25, 1-16. [CrossRef]

4. Ma, X.Y.; Li, C.C.; Sun, L.C.; Huang, D.; Li, T.T.; He, X.P.; Wu, G.W.; Yang, Z.; Zhong, X.Y.; Song, L.B.; et al. Lin28/let-7 axis regulates aerobic glycolysis and cancer progression via PDK1. Nat. Commun. 2014, 5, 1-13. [CrossRef] [PubMed]

5. Karsli-Uzunbas, G.; Guo, J.Y.; Price, S.; Teng, X.; Laddha, S.V.; Khor, S.; Kalaany, N.Y.; Jacks, T.; Chan, C.S.; Rabinowitz, J.D.; et al. Autophagy Is Required for Glucose Homeostasis and Lung Tumor Maintenance. Cancer Discov. 2014, 4, 914-927. [CrossRef] [PubMed] 
6. Zirin, J.; Nieuwenhuis, J.; Perrimon, N. Role of Autophagy in Glycogen Breakdown and Its Relevance to Chloroquine Myopathy. PLoS Biol. 2013, 11, e1001708. [CrossRef]

7. Reinhart, B.J.; Slack, F.J.; Basson, M.; Pasquinelli, A.E.; Bettinger, J.C.; Rougvie, A.E.; Horvitz, H.R.; Ruvkun, G. The 21-nucleotide let-7 RNA regulates developmental timing in Caenorhabditis elegans. Nature 2000, 403, 901-906. [CrossRef]

8. Roush, S.; Slack, F.J. The let-7 family of microRNAs. Trends Cell Biol. 2008, 18, 505-516. [CrossRef]

9. Biamonte, F.; Santamaria, G.; Sacco, A.; Perrone, F.M.; Di Cello, A.; Battaglia, A.M.; Salatino, A.; Di Vito, A.; Aversa, I.; Venturella, R.; et al. MicroRNA let-7g acts as tumor suppressor and predictive biomarker for chemoresistance in human epithelial ovarian cancer. Sci. Rep. 2019, 9, 1-12. [CrossRef]

10. Al-Harbi, B.; Hendrayani, S.F.; Silva, G.; Aboussekhra, A. Let-7b inhibits cancer-promoting effects of breast cancer-associated fibroblasts through IL-8 repression. Oncotarget 2018, 9, 17825-17838. [CrossRef]

11. Lam, W.Y.; Bhattacharya, D. Metabolic Links between Plasma Cell Survival, Secretion, and Stress. Trends Immunol. 2018, 39, 19-27. [CrossRef] [PubMed]

12. Pavlova, N.N.; Thompson, C.B. The Emerging Hallmarks of Cancer Metabolism. Cell Metab. 2016, 23, 27-47. [CrossRef] [PubMed]

13. Katayama, M.; Sjogren, R.J.O.; Egan, B.; Krook, A. miRNA let-7 expression is regulated by glucose and TNF- $\alpha$ by a remote upstream promoter. Biochem. J. 2015, 472, 147-156. [CrossRef]

14. Rawlings-Goss, R.A.; Campbell, M.C.; Tishkoff, S.A. Global population-specific variation in miRNA associated with cancer risk and clinical biomarkers. BMC Med. Genom. 2014, 7, 53. [CrossRef]

15. Serguienko, A.; Grad, I.; Wennerstrom, A.B.; Meza-Zepeda, L.A.; Thiede, B.; Stratford, E.W.; Myklebost, O.; Munthe, E. Metabolic reprogramming of metastatic breast cancer and melanoma by let-7a microRNA. Oncotarget 2015, 6, 2451-2465. [CrossRef]

16. Li, Y.; Lin, J.; Yang, J.; Qian, J.; Qian, W.; Yao, D.M.; Deng, Z.Q.; Liu, Q.; Chen, X.X.; Xie, D.; et al. Overexpressed let-7a-3 is associated with poor outcome in acute myeloid leukemia. Leuk. Res. 2013, 37, 1642-1647. [CrossRef] [PubMed]

17. Shi, J.L.; Fu, L.; Li, Y.H.; Yu, L.; Wang, W.D. Identification of let-7a-2-3p or/and miR-188-5p as Prognostic Biomarkers in Cytogenetically Normal Acute Myeloid Leukemia. PLoS ONE 2015, 10, e0118099. [CrossRef]

18. Hu, N.; Cheng, Z.H.; Pang, Y.F.; Zhao, H.M.; Chen, L.; Wang, C.; Qin, T.; Li, Q.Y.; Han, Y.; Shi, J.L.; et al. High expression of MiR-98 is a good prognostic factor in acute myeloid leukemia patients treated with chemotherapy alone. J. Cancer 2019, 10, 178-185. [CrossRef]

19. Liang, R.; Li, Y.; Wang, M.; Tang, S.C.; Xiao, G.D.; Sun, X.; Li, G.; Du, N.; Liu, D.P.; Ren, H. MiR-146a promotes the asymmetric division and inhibits the self-renewal ability of breast cancer stem-like cells via indirect upregulation of Let-7. Cell Cycle 2018, 17, 1445-1456. [CrossRef]

20. Guo, Q.N.; Wen, R.Y.; Shao, B.; Li, Y.D.; Jin, X.; Deng, H.R.; Wu, J.N.; Su, F.X.; Yu, F.Y. Combined Let-7a and H19 Signature: A Prognostic Index of Progression-Free Survival in Primary Breast Cancer Patients. J. Breast Cancer 2018, 21, 142-149. [CrossRef]

21. Wang, M.; Li, Y.; Xiao, G.D.; Zheng, X.Q.; Wang, J.C.; Xu, C.W.; Qin, S.; Ren, H.; Tang, S.C.; Sun, X. H19 regulation of oestrogen induction of symmetric division is achieved by antagonizing Let-7c in breast cancer stem-like cells. Cell Prolif. 2019, 52, e12534. [CrossRef]

22. Du, J.; Fan, J.J.; Dong, C.; Li, H.T.; Ma, B.L. Inhibition effect of exosomes-mediated Let-7a on the development and metastasis of triple negative breast cancer by down-regulating the expression of c-Myc. Eur. Rev. Med. Pharmacol. Sci. 2019, 23, 5301-5314. [PubMed]

23. Shi, Y.J.; Zhang, Y.N.; Ran, F.; Liu, J.; Lin, J.; Hao, X.P.; Ding, L.H.; Ye, Q.N. Let-7a-5p inhibits triple-negative breast tumor growth and metastasis through GLUT12-mediated warburg effect. Cancer Lett. 2020, 495, 53-65. [CrossRef] [PubMed]

24. Ju, Z.L.; Bhardwaj, A.; Embury, M.D.; Singh, H.; Gunaratne, P.H.; Bedrosian, I.; Wang, J. Integrative Analyses of Multilevel Omics Reveal Preneoplastic Breast to Possess a Molecular Landscape That Is Globally Shared with Invasive Basal-Like Breast Cancer. Cancers 2020, 12, 722. [CrossRef] [PubMed]

25. Bozgeyik, E. Bioinformatic Analysis and in Vitro Validation of Let-7b and Let-7c in Breast Cancer. Comput. Biol. Chem. 2020, 84, 107191. [CrossRef] [PubMed]

26. Li, X.; Liang, T.; Chen, S.S.; Wang, M.; Wang, R.; Li, K.; Wang, J.C.; Xu, C.W.; Du, N.; Qin, S.D.; et al. Matrine suppression of self-renewal was dependent on regulation of LIN28A/Let-7 pathway in breast cancer stem cells. J. Cell. Biochem. 2020, 121, 2139-2149. [CrossRef] [PubMed]

27. Sun, X.; Xu, C.; Tang, S.C.; Wang, J.; Wang, H.; Wang, P.; Du, N.; Qin, S.; Li, G.; Xu, S.; et al. Let-7c blocks estrogen-activated Wnt signaling in induction of self-renewal of breast cancer stem cells. Cancer Gene Ther. 2016, 23, 83-89. [CrossRef]

28. Chen, D.N.; Bao, C.; Zhao, F.; Yu, H.G.; Zhong, G.S.; Xu, L.; Yan, S.X. Exploring Specific miRNA-mRNA Axes with Relationship to Taxanes-Resistance in Breast Cancer. Front. Oncol. 2020, 10, 1397. [CrossRef]

29. Wei, Y.C.; Liu, G.H.; Wu, B.L.; Yuan, Y.F.; Pan, Y.B. Let-7d Inhibits Growth and Metastasis in Breast Cancer by Targeting Jab1/Cops5. Cell. Physiol. Biochem. 2018, 47, 2126-2135. [CrossRef]

30. Qian, P.X.; Zuo, Z.H.; Wu, Z.S.; Meng, X.Y.; Li, G.P.; Wu, Z.Z.; Zhang, W.J.; Tan, S.; Pandey, V.; Yao, Y.D.; et al. Pivotal Role of Reduced let-7g Expression in Breast Cancer Invasion and Metastasis. Cancer Res. 2011, 71, 6463-6474. [CrossRef]

31. Yang, N.; Kaur, S.; Volinia, S.; Greshock, J.; Lassus, H.; Hasegawa, K.; Liang, S.; Leminen, A.; Deng, S.; Smith, L.; et al. MicroRNA Microarray Identifies Let-7i as a Novel Biomarker and Therapeutic Target in Human Epithelial Ovarian Cancer. Cancer Res. 2008, 68, 10307-10314. [CrossRef] [PubMed] 
32. Xu, M.; Kuang, Y.; Wang, M.; Han, X.; Yang, Q. A microRNA expression signature as a predictor of survival for colon adenocarcinoma. Neoplasma 2017, 64, 56-64. [CrossRef] [PubMed]

33. Monzo, M.; Santasusagna, S.; Moreno, I.; Martinez, F.; Hernandez, R.; Munoz, C.; Castellano, J.J.; Moreno, J.; Navarro, A. Exosomal microRNAs isolated from plasma of mesenteric veins linked to liver metastases in resected patients with colon cancer. Oncotarget 2017, 8, 30859-30869. [CrossRef]

34. Sugimura, K.; Miyata, H.; Tanaka, K.; Hamano, R.; Takahashi, T.; Kurokawa, Y.; Yamasaki, M.; Nakajima, K.; Takiguchi, S.; Mori, M.; et al. Let-7 Expression Is a Significant Determinant of Response to Chemotherapy through the Regulation of IL-6/STAT3 Pathway in Esophageal Squamous Cell Carcinoma. Clin. Cancer Res. 2012, 18, 5144-5153. [CrossRef]

35. Tanaka, K.; Miyata, H.; Yamasaki, M.; Sugimura, K.; Takahashi, T.; Kurokawa, Y.; Nakajima, K.; Takiguchi, S.; Mori, M.; Doki, Y. Circulating miR-200c Levels Significantly Predict Response to Chemotherapy and Prognosis of Patients Undergoing Neoadjuvant Chemotherapy for Esophageal Cancer. Ann. Surg. Oncol. 2013, 20, 607-615. [CrossRef] [PubMed]

36. Wang, X.R.; Luo, H.; Li, H.L.; Cao, L.; Wang, X.F.; Yan, W.; Wang, Y.Y.; Zhang, J.X.; Jiang, T.; Kang, C.S.; et al. Overexpressed let-7a inhibits glioma cell malignancy by directly targeting K-ras, independently of PTEN. Neuro Oncol. 2013, 15, 1491-1501. [CrossRef] [PubMed]

37. Santangelo, A.; Rossato, M.; Lombardi, G.; Benfatto, S.; Lavezzari, D.; de Salvo, G.L.; Indraccolo, S.; Dechecchi, M.C.; Prandini, P.; Gambari, R.; et al. A molecular signature associated with prolonged survival in glioblastoma patients treated with regorafenib. Neuro Oncol. 2021, 23, 264-276. [CrossRef]

38. Matos, B.; Bostjancic, E.; Matjasic, A.; Popovic, M.; Glavac, D. Dynamic expression of 11 miRNAs in 83 consecutive primary and corresponding recurrent glioblastoma: Correlation to treatment, time to recurrence, overall survival and MGMT methylation status. Radiol. Oncol. 2018, 52, 422-432. [CrossRef]

39. Erhart, F.; Hackl, M.; Hahne, H.; Buchroithner, J.; Meng, C.; Klingenbrunner, S.; Reitermaier, R.; Fischhuber, K.; Skalicky, S.; Berger, W.; et al. Combined proteomics/miRNomics of dendritic cell immunotherapy-treated glioblastoma patients as a screening for survival-associated factors. NPJ Vaccines 2020, 5, 1-13. [CrossRef]

40. Wang, G.; Bi, C. Correlations of pri-Let-7 gene polymorphisms with the recurrence and metastasis of primary liver cancer after transcatheter arterial chemoembolization. Pathol. Res. Pract. 2018, 214, 667-672. [CrossRef]

41. Tsai, Y.S.; Yeh, M.L.; Tsai, P.C.; Huang, C.I.; Huang, C.F.; Hsieh, M.H.; Liu, T.W.; Lin, Y.H.; Liang, P.C.; Lin, Z.Y.; et al. Clusters of Circulating let-7 Family Tumor Suppressors Are Associated with Clinical Characteristics of Chronic Hepatitis C. Int. J. Mol. Sci. 2020, 21, 4945. [CrossRef]

42. Li, H.; Fang, Z.; Yuan, B.; Ma, S.L.; Li, A.J.; Zhou, W.P.; Zhang, Y.J.; Yin, L. MicroRNA let-7b inhibits cell proliferation via upregulation of p21 in hepatocellular carcinoma. Cell Biosci. 2020, 10,1-12. [CrossRef]

43. Wang, J.G.; Chen, J.L.; Sun, F.; Wang, Z.W.; Xu, W.F.; Yu, Y.F.; Ding, F.; Shen, H.J. miR-202 functions as a tumor suppressor in hepatocellular carcinoma by targeting HK2. Oncol. Lett. 2020, 19, 2265-2271. [CrossRef] [PubMed]

44. Li, Y.M.; Dong, R.; Lu, M.; Cheng, C.L.; Feng, Z.T.; Zhao, R.C.; Liang, J.H.; Han, J.Y.; Jiang, J.; Xu-Welliver, M.; et al. Let-7b-3p inhibits tumor growth and metastasis by targeting the BRF2-mediated MAPK/ERK pathway in human lung adenocarcinoma. Transl. Lung Cancer Res. 2021, 10, 1841-1856. [CrossRef] [PubMed]

45. Li, F.; Li, X.J.; Qiao, L.; Shi, F.; Liu, W.; Li, Y.; Dang, Y.P.; Gu, W.J.; Wang, X.G.; Liu, W. miR-98 suppresses melanoma metastasis through a negative feedback loop with its target gene IL-6. Exp. Mol. Med. 2014, 46, e116. [CrossRef] [PubMed]

46. Truini, A.; Coco, S.; Nadal, E.; Genova, C.; Mora, M.; Dal Bello, M.G.; Vanni, I.; Alama, A.; Rijavec, E.; Biello, F.; et al. Downregulation of miR-99a/let-7c/miR-125b miRNA cluster predicts clinical outcome in patients with unresected malignant pleural mesothelioma. Oncotarget 2017, 8, 68627-68640. [CrossRef] [PubMed]

47. Huang, X.J.; Dong, H.X.; Liu, Y.; Yu, F.; Yang, S.S.; Chen, Z.; Li, J.Y. Silencing of let-7b-5p inhibits ovarian cancer cell proliferation and stemness characteristics by Asp-Glu-Ala-Asp-box helicase 19A. Bioengineered 2021, 12, 7666-7677. [CrossRef]

48. Ye, H.; Chen, J.; Huang, X.; Guo, A.; Hao, P. Construction of let-7d expression vector and its inhibitory effect on HMGA2 and ras expression in human ovarian cancer cells in vitro. Nan Fang Yi Ke Da Xue Xue Bao = J. South. Med. Univ. 2012, 32, $1752-1757$.

49. Xiao, M.; Cai, J.; Cai, L.Q.; Jia, J.H.; Xie, L.S.; Zhu, Y.; Huang, B.X.; Jin, D.D.; Wang, Z.H. Let-7e sensitizes epithelial ovarian cancer to cisplatin through repressing DNA double strand break repair. J. Ovarian Res. 2017, 10, 1-13. [CrossRef]

50. Zheng, H.; Zhang, L.N.; Zhao, Y.R.; Yang, D.; Song, F.J.; Wen, Y.; Hao, Q.; Hu, Z.B.; Zhang, W.; Chen, K.X. Plasma miRNAs as Diagnostic and Prognostic Biomarkers for Ovarian Cancer. PLoS ONE 2013, 8, e77853. [CrossRef]

51. Petrillo, M.; Zannoni, G.F.; Beltrame, L.; Martinelli, E.; DiFeo, A.; Paracchini, L.; Craparotta, I.; Mannarino, L.; Vizzielli, G.; Scambia, G.; et al. Identification of high-grade serous ovarian cancer miRNA species associated with survival and drug response in patients receiving neoadjuvant chemotherapy: A retrospective longitudinal analysis using matched tumor biopsies. Ann. Oncol. 2016, 27, 625-634. [CrossRef]

52. Yang, F.; Zhao, Z.Y.; Cai, S.Y.; Ling, L.; Hong, L.Y.; Tao, L.; Wang, Q. Detailed Molecular Mechanism and Potential Drugs for COL1A1 in Carboplatin-Resistant Ovarian Cancer. Front. Oncol. 2021, 10, 3363. [CrossRef] [PubMed]

53. Dong, L.N.; Cao, X.J.; Luo, Y.; Zhang, G.Q.; Zhang, D.D. A Positive Feedback Loop of lncRNA DSCR8/miR-98-5p/STAT3/HIF-1 alpha Plays a Role in the Progression of Ovarian Cancer. Front. Oncol. 2020, 10, 1713. [CrossRef] [PubMed]

54. Qi, X.; Yu, C.J.; Wang, Y.; Lin, Y.X.; Shen, B.R. Network vulnerability-based and knowledge-guided identification of microRNA biomarkers indicating platinum resistance in high-grade serous ovarian cancer. Clin. Transl. Med. 2019, 8, 1-11. [CrossRef] [PubMed] 
55. Wang, Y.A.; Bao, W.; Liu, Y.; Wang, S.Y.; Xu, S.J.; Li, X.; Li, Y.L.; Wu, S.F. miR-98-5p contributes to cisplatin resistance in epithelial ovarian cancer by suppressing miR-152 biogenesis via targeting Dicer1. Cell Death Dis. 2018, 9, 1-17. [CrossRef]

56. Yu, H.Y.; Pan, S.S. MiR-202-5p suppressed cell proliferation, migration and invasion in ovarian cancer via regulating HOXB2. Eur. Rev. Med. Pharmacol. Sci. 2020, 24, 2256-2263. [CrossRef]

57. Calatayud, D.; Dehlendorff, C.; Boisen, M.K.; Hasselby, J.P.; Schultz, N.A.; Werner, J.; Immervoll, H.; Molven, A.; Hansen, C.P.; Johansen, J.S. Tissue MicroRNA profiles as diagnostic and prognostic biomarkers in patients with resectable pancreatic ductal adenocarcinoma and periampullary cancers. Biomark. Res. 2017, 5, 1-18. [CrossRef]

58. Ali, S.; Almhanna, K.; Chen, W.; Philip, P.A.; Sarkar, F.H. Differentially expressed miRNAs in the plasma may provide a molecular signature for aggressive pancreatic cancer. Am. J. Transl. Res. 2011, 3, $28-47$.

59. Wang, S.J.; Li, X.D.; Wu, L.P.; Guo, P.; Feng, L.X.; Li, B. MicroRNA-202 suppresses glycolysis of pancreatic cancer by targeting hexokinase 2. J. Cancer 2021, 12, 1144-1153. [CrossRef]

60. Schubert, M.; Spahn, M.; Kneitz, S.; Scholz, C.J.; Joniau, S.; Stroebel, P.; Riedmiller, H.; Kneitz, B. Distinct microRNA Expression Profile in Prostate Cancer Patients with Early Clinical Failure and the Impact of let-7 as Prognostic Marker in High-Risk Prostate Cancer. PLoS ONE 2013, 8, e65064. [CrossRef]

61. Jiang, S.; Yan, W.; Wang, S.E.; Baltimore, D. Let-7 Suppresses B Cell Activation through Restricting the Availability of Necessary Nutrients. Cell Metab. 2018, 27, 393-403. [CrossRef] [PubMed]

62. Zhu, W.M.; Huang, Y.J.; Pan, Q.; Xiang, P.; Xie, N.L.; Yu, H. MicroRNA-98 Suppress Warburg Effect by Targeting HK2 in Colon Cancer Cells. Dig. Dis. Sci. 2017, 62, 660-668. [CrossRef] [PubMed]

63. Qin, C.; Lu, R.; Yuan, M.; Zhao, R.; Zhou, H.; Fan, X.; Yin, B.; Yu, H.; Bian, T. Circular RNA 0006349 Augments Glycolysis and Malignance of Non-small Cell Lung Cancer Cells Through the microRNA-98/MKP1 Axis. Front. Cell Dev. Biol. 2021, 9, 690307. [CrossRef]

64. Deng, Y.J.; Li, X.; Feng, J.X.; Zhang, X.L. Overexpression of miR-202 resensitizes imatinib resistant chronic myeloid leukemia cells through targetting Hexokinase 2. Biosci. Rep. 2018, 38, BSR20171383. [CrossRef]

65. Sun, Y.; Chen, Y.; Xu, M.; Liu, C.; Shang, H.; Wang, C. Shenmai Injection Supresses Glycolysis and Enhances Cisplatin Cytotoxicity in Cisplatin-Resistant A549/DDP Cells via the AKT-mTOR-c-Myc Signaling Pathway. BioMed Res. Int. 2020, $2020,9243681$. [CrossRef] [PubMed]

66. Geretto, M.; Pulliero, A.; Rosano, C.; Zhabayeva, D.; Bersimbaev, R.; Izzotti, A. Resistance to cancer chemotherapeutic drugs is determined by pivotal microRNA regulators. Am. J. Cancer Res. 2017, 7, 1350-1371.

67. Li, C.; Chen, L.; Song, W.; Peng, B.; Zhu, J.; Fang, L. DICER activates autophagy and promotes cisplatin resistance in non-small cell lung cancer by binding with let-7i-5p. Acta Histochem. 2021, 123, 151788. [CrossRef]

68. Reinsborough, C.W.; Ipas, H.; Abell, N.S.; Gouws, E.B.; Williams, J.P.; Mercado, M.; Van den Berg, C.; Xhemalce, B. BCDIN3D RNA methyltransferase stimulates Aldolase $\mathrm{C}$ expression and glycolysis through let-7 microRNA in breast cancer cells. Oncogene 2021, 40, 2395-2406. [CrossRef]

69. Chang, Y.C.; Yang, Y.C.; Tien, C.P.; Yang, C.J.; Hsiao, M. Roles of Aldolase Family Genes in Human Cancers and Diseases. Trends Endocrinol. Met. 2018, 29, 549-559. [CrossRef]

70. Guan, M.; Tong, Y.; Guan, M.; Liu, X.; Wang, M.; Niu, R.; Zhang, F.; Dong, D.; Shao, J.; Zhou, Y. Lapatinib Inhibits Breast Cancer Cell Proliferation by Influencing PKM2 Expression. Technol. Cancer Res. Treat. 2018, 17, 1533034617749418. [CrossRef]

71. Jiang, K.; He, B.M.; Lai, L.H.; Chen, Q.Y.; Liu, Y.; Guo, Q.M.; Wang, Q.Q. Cyclosporine A inhibits breast cancer cell growth by downregulating the expression of pyruvate kinase subtype M2. Int. J. Mol. Med. 2012, 30, 302-308. [CrossRef]

72. Yao, A.; Xiang, Y.; Si, Y.R.; Fan, L.J.; Li, J.P.; Li, H.; Guo, W.; He, H.X.; Liang, X.J.; Tan, Y.; et al. PKM2 promotes glucose metabolism through a let-7a-5p/Stat3/hnRNP-A1 regulatory feedback loop in breast cancer cells. J. Cell. Biochem. 2019, 120, 6542-6554. [CrossRef] [PubMed]

73. Luan, W.K.; Wang, Y.Y.; Chen, X.C.; Shi, Y.; Wang, J.J.; Zhang, J.X.; Qian, J.; Li, R.; Tao, T.; Wei, W.; et al. PKM2 promotes glucose metabolism and cell growth in gliomas through a mechanism involving a let-7a/c-Myc/hnRNPA1 feedback loop. Oncotarget 2015, 6, 13006-13018. [CrossRef]

74. Tang, R.; Yang, C.; Ma, X.; Wang, Y.; Luo, D.; Huang, C.; Xu, Z.; Liu, P.; Yang, L. MiR-let-7a inhibits cell proliferation, migration, and invasion by down-regulating PKM2 in gastric cancer. Oncotarget 2016, 7, 5972-5984. [CrossRef]

75. Kuppusamy, K.T.; Jones, D.C.; Sperber, H.; Madan, A.; Fischer, K.A.; Rodriguez, M.L.; Pabon, L.; Zhu, W.Z.; Tulloch, N.L.; Yang, X.L.; et al. Let-7 family of microRNA is required for maturation and adult-like metabolism in stem cell-derived cardiomyocytes. Proc. Natl. Acad. Sci. USA 2015, 112, E2785-E2794. [CrossRef] [PubMed]

76. Lin, Y.; Wei, X.L.; Jian, Z.X.; Zhang, X.W. METTL3 expression is associated with glycolysis metabolism and sensitivity to glycolytic stress in hepatocellular carcinoma. Cancer Med. 2020, 9, 2859-2867. [CrossRef] [PubMed]

77. Cai, X.; Wang, X.; Cao, C.; Gao, Y.; Zhang, S.; Yang, Z.; Liu, Y.; Zhang, X.; Zhang, W.; Ye, L. HBXIP-elevated methyltransferase METTL3 promotes the progression of breast cancer via inhibiting tumor suppressor let-7g. Cancer Lett. 2018, 415, 11-19. [CrossRef]

78. Ruiz-Perez, M.V.; Medina, M.A.; Urdiales, J.L.; Keinanen, T.A.; Sanchez-Jimenez, F. Polyamine Metabolism Is Sensitive to Glycolysis Inhibition in Human Neuroblastoma Cells. J. Biol. Chem. 2015, 290, 6106-6119. [CrossRef]

79. Al Tameemi, W.; Dale, T.P.; Al-Jumaily, R.M.K.; Forsyth, N.R. Hypoxia-Modified Cancer Cell Metabolism. Front. Cell Dev. Biol. 2019, 7, 4. [CrossRef] 
80. Chang, Y.C.; Chan, Y.C.; Chang, W.M.; Lin, Y.F.; Yang, C.J.; Su, C.Y.; Huang, M.S.; Wu, A.T.H.; Hsiao, M. Feedback regulation of ALDOA activates the HIF-1 alpha/MMP9 axis to promote lung cancer progression. Cancer Lett. 2017, 403, 28-36. [CrossRef]

81. Gibadulinova, A.; Bullova, P.; Strnad, H.; Pohlodek, K.; Jurkovicova, D.; Takacova, M.; Pastorekova, S.; Svastova, E. CAIXMediated Control of LIN28/let-7 Axis Contributes to Metabolic Adaptation of Breast Cancer Cells to Hypoxia. Int. J. Mol. Sci. 2020, 21, 4299. [CrossRef]

82. Cai, W.Y.; Wei, T.Z.; Luo, Q.C.; Wu, Q.W.; Liu, Q.F.; Yang, M.; Ye, G.D.; Wu, J.F.; Chen, Y.Y.; Sun, G.B.; et al. The Wnt-beta-catenin pathway represses let-7 microRNA expression through transactivation of Lin28 to augment breast cancer stem cell expansion J. Cell Sci. 2013, 126, 2877-2889. [CrossRef]

83. Cai, C.F.; Ye, G.D.; Shen, D.Y.; Zhang, W.; Chen, M.L.; Chen, X.X.; Han, D.X.; Mi, Y.J.; Luo, Q.C.; Cai, W.Y.; et al. Chibby suppresses aerobic glycolysis and proliferation of nasopharyngeal carcinoma via the Wnt/beta-catenin-Lin28/let7-PDK1 cascade. J. Exp. Clin. Cancer Res. 2018, 37, 104. [CrossRef] [PubMed]

84. Alharris, E.; Singh, N.P.; Nagarkatti, P.S.; Nagarkatti, M. Role of miRNA in the regulation of cannabidiol-mediated apoptosis in neuroblastoma cells. Oncotarget 2019, 10, 45-59. [CrossRef] [PubMed]

85. Sharma, P.; Singh, S. Combinatorial Effect of DCA and Let-7a on Triple-Negative MDA-MB-231 Cells: A Metabolic Approach of Treatment. Integr. Cancer Ther. 2020, 19, 1534735420911437. [CrossRef] [PubMed]

86. Chen, W.F.; Lin, G.S.; Yao, Y.Z.; Chen, J.S.; Shui, H.L.; Yang, Q.H.; Wang, X.Y.; Weng, X.Y.; Sun, L.; Chen, F.; et al. MicroRNA hsa-let-7e-5p as a potential prognosis marker for rectal carcinoma with liver metastases. Oncol. Lett. 2018, 15, 6913-6924. [CrossRef]

87. Xu, G.Y.; Li, J.Y. ATP5A1 and ATP5B are highly expressed in glioblastoma tumor cells and endothelial cells of microvascular proliferation. J. Neuro Oncol. 2016, 126, 405-413. [CrossRef] [PubMed]

88. Duan, S.; Yu, S.; Yuan, T.; Yao, S.; Zhang, L. Exogenous Let-7a-5p Induces A549 Lung Cancer Cell Death Through BCL2L1Mediated PI3Kgamma Signaling Pathway. Front. Oncol. 2019, 9, 808. [CrossRef]

89. Fan, H.; Jiang, M.; Li, B.; He, Y.; Huang, C.; Luo, D.; Xu, H.; Yang, L.; Zhou, J. MicroRNA-let-7a regulates cell autophagy by targeting Rictor in gastric cancer cell lines MGC-803 and SGC-7901. Oncol. Rep. 2018, 39, 1207-1214. [CrossRef]

90. Gao, Y.; Zhang, X.; Meng, T. Overexpression of let-7b exerts beneficial effects on the functions of human placental trophoblasts by activating the ERK1/2 signaling pathway. Mol. Reprod. Dev. 2021,1-15. [CrossRef]

91. Yang, Z.Y.; Wang, Y.; Liu, Q.; Wu, M. microRNA cluster MC-let-7a-1 let-7d promotes autophagy and apoptosis of glioma cells by down-regulating STAT3. CNS Neurosci. Ther. 2020, 26, 319-331. [CrossRef] [PubMed]

92. Liang, H.; Xu, M.X.; Xiong, Z.Y.; Hu, K.P.; Yang, J.R.; Cao, M.B.; Zhong, Z.Z.; Yao, Z.C.; Deng, M.H.; Liu, B. Identification of miRNAs as diagnostic and prognostic markers in hepatocellular carcinoma. Aging 2021, 13, 6115-6133. [CrossRef] [PubMed]

93. Pan, X.; Wang, G.; Wang, B. MicroRNA-1182 and let-7a exert synergistic inhibition on invasion, migration and autophagy of cholangiocarcinoma cells through down-regulation of NUAK1. Cancer Cell Int. 2021, 21, 161. [CrossRef]

94. Xiong, H.; Shen, J.; Chen, Z.; Yang, J.; Xie, B.; Jia, Y.; Jayasinghe, U.; Wang, J.; Zhao, W.; Xie, S.; et al. H19/let7/Lin28 ceRNA network mediates autophagy inhibiting epithelialmesenchymal transition in breast cancer. Int. J. Oncol. 2020, 56, 794-806. [CrossRef] [PubMed]

95. Han, C.C.; Li, H.; Ma, Z.F.; Dong, G.Z.; Wang, Q.Y.; Wang, S.W.; Fang, P.Q.; Li, X.; Chen, H.; Liu, T.Y.; et al. MIR99AHG is a noncoding tumor suppressor gene in lung adenocarcinoma. Cell Death Dis. 2021, 12, 1-16. [CrossRef]

96. Liao, C.C.; Ho, M.Y.; Liang, S.M.; Liang, C.M. Recombinant protein rVP1 upregulates BECN1-independent autophagy, MAPK1/3 phosphorylation and MMP9 activity via WIPI1/WIPI2 to promote macrophage migration. Autophagy 2013, 9, 5-19. [CrossRef]

97. Liao, C.C.; Ho, M.Y.; Liang, S.M.; Liang, C.M. Autophagic degradation of SQSTM1 inhibits ovarian cancer motility by decreasing DICER1 and AGO2 to induce MIRLET7A-3P. Autophagy 2018, 14, 2065-2082. [CrossRef]

98. Mohamed, I.S.E.; Sen'kova, A.V.; Nadyrova, A.I.; Savin, I.A.; Markov, A.V.; Mitkevich, V.A.; Makarov, A.A.; Ilinskaya, O.N.; Mironova, N.L.; Zenkova, M.A. Antitumour Activity of the Ribonuclease Binase from Bacillus pumilus in the RLS40 Tumour Model Is Associated with the Reorganisation of the miRNA Network and Reversion of Cancer-Related Cascades to Normal Functioning. Biomolecules 2020, 10, 1509. [CrossRef]

99. Xu, W.; Ding, M.; Wang, B.; Cai, Y.; Guo, C.; Yuan, C. Molecular mechanism of the canonical oncogenic lncRNA MALAT1 in gastric cancer. Curr. Med. Chem. 2021. [CrossRef]

100. Yang, W.; Gong, P.; Yang, Y.; Yang, C.; Yang, B.; Ren, L. Circ-ABCB10 Contributes to Paclitaxel Resistance in Breast Cancer through Let-7a-5p/DUSP7 Axis. Cancer Manag. Res. 2020, 12, 2327-2337. [CrossRef]

101. Pannuru, P.; Dontula, R.; Khan, A.A.; Herbert, E.; Ozer, H.; Chetty, C.; Lakka, S.S. miR-let-7f-1 regulates SPARC mediated cisplatin resistance in medulloblastoma cells. Cell. Signal. 2014, 26, 2193-2201. [CrossRef]

102. Duan, S.Y.; Li, J.X.; Tian, J.Q.; Yin, H.Y.; Zhai, Q.F.; Wu, Y.J.; Yao, S.Q.; Zhang, L. Crosstalk between let-7a-5p and BCL-xL in the Initiation of Toxic Autophagy in Lung Cancer. Mol. Ther. Oncolytics 2019, 15, 69-78. [CrossRef] [PubMed]

103. Lai, H.H.; Li, J.N.; Wang, M.Y.; Huang, H.Y.; Croce, C.M.; Sun, H.L.; Lyu, Y.J.; Kang, J.W.; Chiu, C.F.; Hung, M.C.; et al. HIF-1alpha promotes autophagic proteolysis of Dicer and enhances tumor metastasis. J. Clin. Investig. 2018, 128, 625-643. [CrossRef] [PubMed]

104. Egea, V.; Kessenbrock, K.; Lawson, D.; Bartelt, A.; Weber, C.; Ries, C. Let-7f miRNA regulates SDF-1alpha- and hypoxia-promoted migration of mesenchymal stem cells and attenuates mammary tumor growth upon exosomal release. Cell Death Dis. 2021, 12, 516. [CrossRef] 
105. Fang, F.; Shi, X.; Brown, M.S.; Goldstein, J.L.; Liang, G. Growth hormone acts on liver to stimulate autophagy, support glucose production, and preserve blood glucose in chronically starved mice. Proc. Natl. Acad. Sci. USA 2019, 116, 7449-7454. [CrossRef] [PubMed]

106. Zhu, X.; Li, Y.; Xu, G.; Fu, C. Growth hormone receptor promotes breast cancer progression via the BRAF/MEK/ERK signaling pathway. FEBS Open Bio 2020, 10, 1013-1020. [CrossRef]

107. Recouvreux, M.V.; Wu, J.B.; Gao, A.C.; Zonis, S.; Chesnokova, V.; Bhowmick, N.; Chung, L.W.; Melmed, S. Androgen Receptor Regulation of Local Growth Hormone in Prostate Cancer Cells. Endocrinology 2017, 158, 2255-2268. [CrossRef] [PubMed]

108. Elzein, S.; Goodyer, C.G. Regulation of human growth hormone receptor expression by microRNAs. Mol. Endocrinol. 2014, 28, 1448-1459. [CrossRef]

109. Tahtouh, R.; Wardi, L.; Sarkis, R.; Hachem, R.; Raad, I.; El Zein, N.; Hilal, G. Glucose restriction reverses the Warburg effect and modulates PKM2 and mTOR expression in breast cancer cell lines. Cell. Mol. Biol. 2019, 65, 26-33. [CrossRef]

110. Zhou, J.; Bi, C.; Ching, Y.Q.; Chooi, J.Y.; Lu, X.; Quah, J.Y.; Toh, S.H.; Chan, Z.L.; Tan, T.Z.; Chong, P.S.; et al. Inhibition of LIN28B impairs leukemia cell growth and metabolism in acute myeloid leukemia. J. Hematol. Oncol. 2017, 10, 138. [CrossRef]

111. Ackermann, T.; Hartleben, G.; Muller, C.; Mastrobuoni, G.; Groth, M.; Sterken, B.A.; Zaini, M.A.; Youssef, S.A.; Zuidhof, H.R.; Krauss, S.R.; et al. C/EBPbeta-LIP induces cancer-type metabolic reprogramming by regulating the let-7/LIN28B circuit in mice. Commun. Biol. 2019, 2, 208. [CrossRef]

112. Peker, N.; Gozuacik, D. Autophagy as a Cellular Stress Response Mechanism in the Nervous System. J. Mol. Biol. 2020, 432, 2560-2588. [CrossRef]

113. Jung, C.H.; Jun, C.B.; Ro, S.H.; Kim, Y.M.; Otto, N.M.; Cao, J.; Kundu, M.; Kim, D.H. ULK-Atg13-FIP200 Complexes Mediate mTOR Signaling to the Autophagy Machinery. Mol. Biol. Cell 2009, 20, 1992-2003. [CrossRef] [PubMed]

114. Wan, H.; Xu, L.; Zhang, H.; Wu, F.; Zeng, W.; Li, T. High expression of NEK2 promotes gastric cancer progression via activating AKT signaling. J. Physiol. Biochem. 2021, 77, 25-34. [CrossRef] [PubMed]

115. Dai, H.; Hu, W.; Zhang, L.; Jiang, F.; Mao, X.; Yang, G.; Li, L. FGF21 facilitates autophagy in prostate cancer cells by inhibiting the PI3K-Akt-mTOR signaling pathway. Cell Death Dis. 2021, 12, 303. [CrossRef] [PubMed]

116. Gao, Y.; Wu, F.; Zhou, J.; Yan, L.; Jurczak, M.J.; Lee, H.Y.; Yang, L.; Mueller, M.; Zhou, X.B.; Dandolo, L.; et al. The H19/let-7 double-negative feedback loop contributes to glucose metabolism in muscle cells. Nucleic Acids Res. 2014, 42, 13799-13811. [CrossRef]

117. Kang, M.; Lee, K.H.; Lee, H.S.; Jeong, C.W.; Ku, J.H.; Kim, H.H.; Kwak, C. Concurrent treatment with simvastatin and NFkappaB inhibitor in human castration-resistant prostate cancer cells exerts synergistic anti-cancer effects via control of the NF-kappaB/LIN28/let-7 miRNA signaling pathway. PLoS ONE 2017, 12, e0184644. [CrossRef]

118. Liang, X.H.; Yu, M.Z.; Shi, H.L.; Wu, X.J. Galangin enhances autophagy by inhibiting NF-kappaB pathway in gastric cancer MGC-803 cells. Zhongguo Zhong yao za zhi= Zhongguo Zhongyao Zazhi= China J. Chin. Mater. Med. 2021, 46, 4167-4174. [CrossRef]

119. Lee, S.; Dong, H.H. FoxO integration of insulin signaling with glucose and lipid metabolism. J. Endocrinol. 2017, 233, R67-R79. [CrossRef]

120. Sin, T.K.; Yung, B.Y.; Siu, P.M. Modulation of SIRT1-Foxo1 signaling axis by resveratrol: Implications in skeletal muscle aging and insulin resistance. Cell. Physiol. Biochem. 2015, 35, 541-552. [CrossRef]

121. Ciccarone, F.; Di Leo, L.; Lazzarino, G.; Maulucci, G.; Di Giacinto, F.; Tavazzi, B.; Ciriolo, M.R. Aconitase 2 inhibits the proliferation of MCF-7 cells promoting mitochondrial oxidative metabolism and ROS/FoxO1-mediated autophagic response. Br. J. Cancer 2020, 122, 182-193. [CrossRef]

122. Baldelli, S.; Aquilano, K.; Ciriolo, M.R. PGC-1alpha buffers ROS-mediated removal of mitochondria during myogenesis. Cell Death Dis. 2014, 5, e1515. [CrossRef] [PubMed]

123. Ozates, N.P.; Sogutlu, F.; Lerminoglu, F.; Demir, B.; Gunduz, C.; Shademan, B.; Avci, C.B. Effects of rapamycin and AZD3463 combination on apoptosis, autophagy, and cell cycle for resistance control in breast cancer. Life Sci. 2021, 264, 118643. [CrossRef] [PubMed]

124. Hopkins, B.L.; Nadler, M.; Skoko, J.J.; Bertomeu, T.; Pelosi, A.; Shafaei, P.M.; Levine, K.; Schempf, A.; Pennarun, B.; Yang, B.; et al. A Peroxidase Peroxiredoxin 1-Specific Redox Regulation of the Novel FOXO3 microRNA Target let-7. Antioxid. Redox Signal. 2018, 28, 62-77. [CrossRef]

125. Huang, J.; Lin, H.; Zhong, M.; Huang, J.; Sun, S.; Lin, L.; Chen, Y. Role of Lin28A/let-7a/c-Myc Pathway in Growth and Malignant Behavior of Papillary Thyroid Carcinoma. Med. Sci. Monit. 2018, 24, 8899-8909. [CrossRef] [PubMed]

126. Jin, K.; Su, K.K.; Li, T.; Zhu, X.Q.; Wang, Q.; Ge, R.S.; Pan, Z.F.; Wu, B.W.; Ge, L.J.; Zhang, Y.H.; et al. Hepatic Premalignant Alterations Triggered by Human Nephrotoxin Aristolochic Acid I in Canines. Cancer Prev. Res. 2016, 9, 324-334. [CrossRef]

127. Qian, X.; Li, X.; Cai, Q.; Zhang, C.; Yu, Q.; Jiang, Y.; Lee, J.H.; Hawke, D.; Wang, Y.; Xia, Y.; et al. Phosphoglycerate Kinase 1 Phosphorylates Beclin1 to Induce Autophagy. Mol. Cell 2017, 65, 917-931.e916. [CrossRef]

128. Ariosa, A.R.; Klionsky, D.J. A novel role for a glycolytic pathway kinase in regulating autophagy has implications in cancer therapy. Autophagy 2017, 13, 1091-1092. [CrossRef]

129. Yu, T.; Zhao, Y.; Hu, Z.; Li, J.; Chu, D.; Zhang, J.; Li, Z.; Chen, B.; Zhang, X.; Pan, H.; et al. MetaLnc9 Facilitates Lung Cancer Metastasis via a PGK1-Activated AKT/mTOR Pathway. Cancer Res. 2017, 77, 5782-5794. [CrossRef] 
130. De Mello, R.A.; Aguiar, P.N.; Tadokoro, H.; Farias-Vieira, T.M.; Castelo-Branco, P.; Lopes, G.D.; Pozza, D.H. MetaLanc9 as a novel biomarker for non-small cell lung cancer: Promising treatments via a PGK1-activated AKT/mTOR pathway. J. Thorac. Dis. 2018, 10, S2076-S2078. [CrossRef]

131. Fu, D.Y.; He, C.L.; Wei, J.L.; Zhang, Z.Q.; Luo, Y.L.; Tan, H.S.; Ren, C.L. PGK1 is a Potential Survival Biomarker and Invasion Promoter by Regulating the HIF-1 alpha-Mediated Epithelial-Mesenchymal Transition Process in Breast Cancer. Cell. Physiol. Biochem. 2018, 51, 2434-2444. [CrossRef] [PubMed]

132. Xie, H.J.; Tong, G.H.; Zhang, Y.P.; Liang, S.; Tang, K.R.; Yang, Q.H. PGK1 Drives Hepatocellular Carcinoma Metastasis by Enhancing Metabolic Process. Int. J. Mol. Sci. 2017, 18, 1630. [CrossRef] [PubMed]

133. Wu, Y. Pim1 promotes cell proliferation and regulates glycolysis via interaction with c-MYC in ovarian cancer. Gynecol. Oncol. 2019, 154, 70. [CrossRef]

134. Xu, D.; Aka, J.A.; Wang, R.X.; Lin, S.X. 17beta-hydroxysteroid dehydrogenase type 5 is negatively correlated to apoptosis inhibitor GRP78 and tumor-secreted protein PGK1, and modulates breast cancer cell viability and proliferation. J. Steroid Biochem. Mol. Biol. 2017, 171, 270-280. [CrossRef]

135. Peng, M.X.; Yang, D.; Hou, Y.X.; Liu, S.Q.; Zhao, M.J.; Qin, Y.L.; Chen, R.; Teng, Y.; Liu, M.R. Intracellular citrate accumulation by oxidized ATM-mediated metabolism reprogramming via PFKP and CS enhances hypoxic breast cancer cell invasion and metastasis. Cell Death Dis. 2019, 10, 1-16. [CrossRef]

136. Agnarelli, A.; Natali, M.; Garcia-Gil, M.; Pesi, R.; Tozzi, M.G.; Ippolito, C.; Bernardini, N.; Vignali, R.; Batistoni, R.; Bianucci, A.M.; et al. Cell-specific pattern of berberine pleiotropic effects on different human cell lines. Sci. Rep. 2018, 8, 10599. [CrossRef]

137. New, M.; Van Acker, T.; Sakamaki, J.I.; Jiang, M.; Saunders, R.E.; Long, J.; Wang, V.M.; Behrens, A.; Cerveira, J.; Sudhakar, P.; et al. MDH1 and MPP7 Regulate Autophagy in Pancreatic Ductal Adenocarcinoma. Cancer Res. 2019, 79, 1884-1898. [CrossRef]

138. Liu, H.Y.; Zhang, H.S.; Liu, M.Y.; Li, H.M.; Wang, X.Y.; Wang, M. GLS1 depletion inhibited colorectal cancer proliferation and migration via redox/Nrf2/autophagy-dependent pathway. Arch. Biochem. Biophys. 2021, 708, 108964. [CrossRef]

139. Mukha, A.; Kahya, U.; Dubrovska, A. Targeting glutamine metabolism and autophagy: The combination for prostate cancer radiosensitization. Autophagy 2021, 17, 1-3. [CrossRef]

140. Mukha, A.; Kahya, U.; Linge, A.; Chen, O.; Lock, S.; Lukiyanchuk, V.; Richter, S.; Alves, T.C.; Peitzsch, M.; Telychko, V.; et al. GLS-driven glutamine catabolism contributes to prostate cancer radiosensitivity by regulating the redox state, stemness and ATG5-mediated autophagy. Theranostics 2021, 11, 7844-7868. [CrossRef]

141. Xia, M.; Li, X.; Diao, Y.; Du, B.; Li, Y. Targeted inhibition of glutamine metabolism enhances the antitumor effect of selumetinib in KRAS-mutant NSCLC. Transl. Oncol. 2021, 14, 100920. [CrossRef] [PubMed]

142. Bruntz, R.C.; Belshoff, A.C.; Zhang, Y.; Macedo, J.K.A.; Higashi, R.M.; Lane, A.N.; Fan, T.W. Inhibition of Anaplerotic Glutaminolysis Underlies Selenite Toxicity in Human Lung Cancer. Proteomics 2019, 19, e1800486. [CrossRef] [PubMed]

143. Park, S.H.; Kim, J.H.; Chi, G.Y.; Kim, G.Y.; Chang, Y.C.; Moon, S.K.; Nam, S.W.; Kim, W.J.; Yoo, Y.H.; Choi, Y.H. Induction of apoptosis and autophagy by sodium selenite in A549 human lung carcinoma cells through generation of reactive oxygen species. Toxicol. Lett. 2012, 212, 252-261. [CrossRef] [PubMed]

144. Clemente, G.S.; van Waarde, A.; Antunes, I.F.; Domling, A.; Elsinga, P.H. Arginase as a Potential Biomarker of Disease Progression: A Molecular Imaging Perspective. Int. J. Mol. Sci. 2020, 21, 5291. [CrossRef]

145. Wang, Z.; Xie, Q.; Zhou, H.; Zhang, M.; Shen, J.; Ju, D. Amino Acid Degrading Enzymes and Autophagy in Cancer Therapy. Front. Pharmacol. 2020, 11, 582587. [CrossRef] [PubMed]

146. Yang, J.S.; Wang, C.C.; Qiu, J.D.; Ren, B.; You, L. Arginine metabolism: A potential target in pancreatic cancer therapy. Chin. Med. I. 2020, 134, 28-37. [CrossRef]

147. Poillet-Perez, L.; Xie, X.Q.; Zhan, L.; Yang, Y.; Sharp, D.W.; Hu, Z.S.; Su, X.Y.; Maganti, A.; Jiang, C.; Lu, W.Y.; et al. Autophagy maintains tumour growth through circulating arginine. Nature 2019, 565, E3. [CrossRef]

148. Swayden, M.; Bekdash, A.; Fakhoury, I.; El-Atat, O.; Borjac-Natour, J.; El-Sibai, M.; Abi-Habib, R.J. Activation of autophagy following [HuArgI (Co)-PEG5000]-induced arginine deprivation mediates cell death in colon cancer cells. Hum. Cell 2021, 34, 152-164. [CrossRef]

149. Xia, H.J.; Li, S.S.; Li, X.; Wang, W.C.; Bian, Y.J.; Wei, S.; Grove, S.; Wang, W.M.; Vatan, L.D.; Liu, J.R.; et al. Autophagic adaptation to oxidative stress alters peritoneal residential macrophage survival and ovarian cancer metastasis. JCI Insight 2020, 5, e141115. [CrossRef]

150. Kim, J.; Kundu, M.; Viollet, B.; Guan, K.L. AMPK and mTOR regulate autophagy through direct phosphorylation of Ulk1. Nat. Cell Biol. 2011, 13, 132-141. [CrossRef]

151. Simino, L.A.P.; Panzarin, C.; Fontana, M.F.; de Fante, T.; Geraldo, M.V.; Ignacio-Souza, L.M.; Milanski, M.; Torsoni, M.A.; Ross, M.G.; Desai, M.; et al. MicroRNA Let-7 targets AMPK and impairs hepatic lipid metabolism in offspring of maternal obese pregnancies. Sci. Rep. 2021, 11, 8980. [CrossRef] [PubMed]

152. Zhong, T.; Men, Y.; Lu, L.; Geng, T.; Zhou, J.; Mitsuhashi, A.; Shozu, M.; Maihle, N.J.; Carmichael, G.G.; Taylor, H.S.; et al. Metformin alters DNA methylation genome-wide via the H19/SAHH axis. Oncogene 2017, 36, 2345-2354. [CrossRef] [PubMed]

153. Wei, J.; Xie, Q.; Liu, X.; Wan, C.; Wu, W.; Fang, K.; Yao, Y.; Cheng, P.; Deng, D.; Liu, Z. Identification the prognostic value of glutathione peroxidases expression levels in acute myeloid leukemia. Ann. Transl. Med. 2020, 8, 678. [CrossRef] 
154. Chen, L.; Guo, L.; Sun, Z.W.; Yang, G.C.; Guo, J.; Chen, K.; Xiao, R.X.; Yang, X.G.; Sheng, L.J. Monoamine Oxidase A is a Major Mediator of Mitochondria! Homeostasis and Glycolysis in Gastric Cancer Progression. Cancer Manag. Res. 2020, 12, 8023-8035. [CrossRef]

155. Huang, Y.; Zhao, W.; Ouyang, X.; Wu, F.; Tao, Y.; Shi, M. Monoamine Oxidase a Inhibits Lung Adenocarcinoma Cell Proliferation by Abrogating Aerobic Glycolysis. Front. Oncol. 2021, 11, 645821. [CrossRef] [PubMed]

156. Lin, Y.C.; Chang, Y.T.; Campbell, M.; Lin, T.P.; Pan, C.C.; Lee, H.C.; Shih, J.C.; Chang, P.C. MAOA-a novel decision maker of apoptosis and autophagy in hormone refractory neuroendocrine prostate cancer cells. Sci. Rep. 2017, 7, 46338. [CrossRef] 